\title{
LOS BUDDENBROOK Y EL ESPIRITU DEL CAPITALISMO. Afinidades electivas entre Thomas Mann y Max Weber
}

\author{
Fernando Bayón Martín
}

For what is Antichrist but those Who against Sinners Heaven close With Irons bars, in Virtous State, And Rhadamanthus at the Gate?

$(\text { William Blake })^{1}$

\section{Introducción}

El novelista francés Gustav Flaubert, que con ascética reciedumbre había ofrecido toda su vida al ídolo nihilista de la litterature, hizo cierto día una visita a una familia amiga de su sobrina la señora Commanville. Integraban la familia el feliz matrimonio y sus encantadores hijos. De regreso, el autor de Madame Bovary se mostró especialmente pensativo. Indudablemente, aquella visita de cortesía había removido su interior. Mientras bordeaba el Sena en compañía de su sobrina, volvía una y otra vez en su conversación sobre la vida natural, sana, serena, honesta y respetable que acababa de observar: Ils sont dans le vrai!, repetía, y esta frase, semejante a una negación de sí mismo, en la boca del maestro que se había ejercitado en mortificar y en asesinar su vida, que había hecho de ello un deber para el artista ${ }^{2}$, era una cita favorita de Franz Kafka.

El recuerdo de esta anécdota y su remite al escritor de Praga corresponden a Thomas Mann, quien, en un breve ensayo dedicado a la novela El castillo y con la mayor economía de medios, introduce al lector en una de las más delicadas visiones del hecho creativo: el arte como expresión ética de la vida. Bajo la mirada que Mann proyecta sobre

\footnotetext{
* Este trabajo ha sido realizado con la ayuda de una beca del Ministerio de Educación y Cultura.

1 Pues, ¿qué es el Anticristo sino aquellos/ que cierran el Cielo al Pecador,/Virtuosamente, con barras de Hierro,/ Y Radamante en los Portales? BlaKe, William, «The Everlasting Gospel», en Antología bilingüe, Madrid, Alianza, 1987, p. 208.

2 Mann, Thomas, «Franz Kafka y "El Castillo"», en El artista y la sociedad, Madrid, Guadarrama, 1975, p. 242.
} 
Kafka, la estética y la ética, dos reinos puestos en relación de modo reduccionista por aquellos irreductibles de uno cualquiera de los dos «bandos», se avienen a un mutuo pero desgarrador entendimiento. Vivir en Dios, en la verdad, actuar justamente, vivir al abrigo, no ha dejado de ser la secreta aspiración en el corazón de algunos de los artistas más destacados de este siglo desencantado que parecería promover en sus almas más creativas la efusiva solidaridad con un tiempo de libertad sin coacciones religiosas ni morales. En cambio, la inquietud religiosa ha embargado la libre fluencia de la subjetividad creadora. Acaso podría probarse que este embargo ha sido el rudimento espiritual de los más altos logros artísticos del siglo Xx, que son, por lo demás, los que han penetrado más lúcidamente el tiempo que los vio nacer.

Esta inquietud y desgarro apuntan como a una de sus causas principales a la comprensión de la creación literaria como trabajo, aspiración única, vocación. El joven Kafka recordaba en el albor de la Primera Guerra Mundial cómo aquel vivir en Dios y actuar con justicia se revestía con un tinte de accesoriedad ante la fuerza inexpugnable que le inclinaba a representar el sueño de mi vida interior. A menudo me siento preso de un asombro triste, pero tranquilo, al constatar mi indiferencia, como consecuencia de mi vocación literaria, no tengo interés alguno por otra cosa y, en consecuencia, tengo el corazón seco ${ }^{3}$. No se está aquí formulando simplemente una nueva versión de la oposición, masivamente atribuida también a la obra de Mann, entre arte y vida, sino algo más sustancial y, desde la perspectiva de este trabajo, mucho más interesante: aquí se expresa el artista a través de una cualificación nueva del término vocación. Esta no constituye una mera opción vital sino un símbolo ético.

La cualificación simbólica del término vocación va a ser decisiva para nuestras intenciones. La pasión por el arte supone un alejamiento de Dios. Y esta lejanía genera desazón. Ahora bien, el signo de esta desazón es inequívocamente religioso: la respuesta del literato a su vocación genera una profunda remoción interior. Lo que nos dice Thomas Mann al respecto de Franz Kafka es que es posible comprender simbólicamente la pasión en que se sustancia la vocación del novelista, la misma pasión que le hace mostrarse indiferente ante el resto de estímulos humanos. Es posible ver ahí un símbolo ético: $E l$ arte no es necesariamente el producto, el sentido y la meta de la negación orgíaca y ascética de la vida, como en Flaubert. Puede ser una

\footnotetext{
${ }^{3}$ Citado por ManN en Ibid., pp. 242-243.
} 
expresión ética de la vida misma y lo que esté en juego no ser la obra, sino la vida ${ }^{4}$.

El hecho creador se resiste a ser explicado por la aplicación mera de la recurrente oposición arte/vida: el carácter éticamente simbólico de la pasión artística entendida como respuesta personal a una vocación impersonal consigue trasladar el terreno de juego del arte desde el ámbito de sus productos materiales hasta el reino de la vida. De este modo, la vida deja de ser un simple medio de alcanzar un ideal de perfección estética. El trabajo, racional, regular, organizado, se convierte en símbolo ético de la vida, su meta - sigue diciendo Mann- no es una perfección objetiva cualquiera, sino la conciencia subjetiva de haber actuado lo mejor posible y de haber empleado su existencia juiciosamente en otra obra, humana, de valor equivalente. La inexpugnable inclinación hacia el trabajo, la apasionada dedicación, ¿pueden acaso revelar un sustrato religioso en la vocación del literato? Sería arriesgado comprometer en la respuesta a la generalidad de los destinos literarios. En atención al caso de Kafka, Thomas Mann esgrime argumentos decisivos para responder afirmativamente: en esa dedicación diaria, en ese trabajo, Kafka no halla únicamente un medio, obviamente necesario, para la perfección de su arte, el acabamiento real de su talento y la plasmación efectiva de su ideal estético; en esa inclinación hacia el trabajo, desgarradora en ocasiones, el autor de América encuentra una justificación. Unicamente en el trabajo conoce la vida de Franz Kafka una mejora.

La introducción de ideas tales como justificación y mejora en un discurso referido al quehacer artístico descubre sorprendentes afinidades entre este ámbito de intervención humana y el ámbito de la vivencia religiosa. Efectivamente, encontrar una justificación para mi vida significa derivarla de un valor que no estoy en condiciones de discutir. $\mathrm{Y}$ aquello frente a lo cual me siento incapaz de crítica es lo que puedo denominar como sagrado. Hallar una justificación a algo del orden terreno, máxime si se trata de una vida, es remitirlo a un orden sagrado que lo autentifique. Este remite implica una mediación, es decir, el descubrimiento de un vínculo entre uno y otro orden. Si nuestra pregunta por la justificación afectara al conjunto de relaciones que constituyen las instituciones sociales podríamos proponer — como hicieron los románticos alemanes- que dicho vínculo es el mito. Efectivamente, uno de los rendimientos de los relatos míticos, cuando éstos son algo vivo, tiene que ver con ese desplazamiento de algo desde el mundo natural o

\footnotetext{
4 Ibidem, p. 243.
} 
humano hasta la esfera de lo sagrado. El relato mítico cobra tal fuerza vinculante y normativa en la medida en que ese algo del orden mundano que por mediación suya es desplazado hasta la esfera sagrada es fundado a través de ese desplazamiento ${ }^{5}$. Aquí, sin embargo, la pregunta por la justificación afecta al conjunto de relaciones que constituyen la identidad personal en la medida en que esas relaciones se entienden como respuesta a una vocación: Me he puesto a escribir después de varios días - dice una vez Kafka - ;Ojalá dure! Mi vida encuentra una justificación. Puedo de nuevo dialogar conmigo mismo y no poner más la vista en un vacío absoluto. Unicamente de esta forma he podido conocer una mejora ${ }^{6}$. El interés del concepto vocación estriba en desplazar el centro de gravedad del arte desde la idea objetiva de perfección hacia la conciencia subjetiva de justificación. Esto significa entrar en el reino del sentido, no ya intelectual, sino moral, del arte. Como nos dice Mann en su ensayo, da igual que el autor de El castillo haya empleado la palabra mejora en vez de salvación, aunque el sentido religioso de aquel poder dialogar conmigo mismo y no poner más la vista en un vacío absoluto por medio del trabajo hubiera sido aún más sensible.

Es el trabajo, entendido bajo la influencia tutelar de la idea de vocación, lo que sirve de vínculo y mediación entre el orden de la vida y la esfera del valor. Es el trabajo lo que autentifica una vida de poeta y revela el sustrato íntimamente religioso de su inexpugnable inclinación creativa. Mann recuerda la cita de Goethe: «Uno no se sustrae al mundo más fácilmente que por el arte y no se vincula al mundo más fácilmente que por el arte.» Nos proponemos analizar este balanceo entre alejamiento de la verdad y elevación a la verdad, este vivir en Dios a la sombra de Dios, e investigar la profundidad simbólica de la idea del Bien a través de un estudio de la obra de Mann que hace centro en uno de sus personajes: Hanno Buddenbrook, el protagonista final de Los Buddenbrook, la primera gran novela del autor. E1 arco temporal que separa al postrer representante de los Buddenbrook de sus ascendientes fundadores de la saga será estudiado aquí a la luz de algunos motivos de la filosofía de Max Weber que esta novela articula de modo muy personal al tiempo que extrañamente fiel (aunque en honor a la formación,

5 Para el análisis del concepto de justificación como uno de los rendimientos principales de los relatos míticos según la filosofía del romanticismo alemán, véase Frank, MANFRED, Kaltes Herz, Unendliche Fahrt, Neue Mythologie, Suhrkamp, Frankfurt, 1989. Véase Nueva Mitología, traducción incluida en OrTiz-Osés, A., y LANCERos, P., directores, Diccionario de Hermenéutica, Bilbao, Universidad de Deusto, 1997, pp. 578-86. También su libro: Der Kommende Gott, Suhrkamp, Frankfurt, 1982.

${ }^{6}$ MAnN, Thomas, supra, p. 243. 
pretensiones, método de trabajo, y, sobre todo, a los logros de Mann sería ilegítimo, y extravagante, querer dar a entender que éste se propuso hacer de una sola de sus novelas una relectura o reelaboración de las tesis defendidas por Weber). Nos fijaremos particularmente en el concepto de vocación desarrollado en sus dos conferencias, Politik als Beruf (Política como vocación) y Wissenschaft als Beruf ${ }^{7}$ (Ciencia como vocación), y en el concepto de ascesis, profusamente analizado a raíz de sus investigaciones acerca de la religiosidad protestante y que le ocupa en su obra más conocida La ética protestante y el espíritu del capitalismo.

Como en el caso de Franz Kafka, Thomas Mann plantea el problema de la vocación al respecto de cada uno de los miembros de la estirpe Buddenbrook y lo hace con profundos y demoledores intereses dramáticos. Pero bajo estos intereses operan indisimuladamente otros que, sin contravenir los anteriores, antes al contrario reforzándolos, fundándolos, pueden interpretarse como afines a la investigación weberiana acerca de los dos motivos citados. Es indudable que una mirada pronta dirigida hacia los dos pensadores traería a primer plano una cierta contradicción: si el término desencantamiento (Entzauberung) ha hecho fortuna en los más variados foros de debate sociocultural ello es debido a la penetración y justedad de las investigaciones que sobre el tema realizó Max Weber, algunas de las cuales comportan el sello de lo definitivo; si, por su parte, cuestionáramos a cualquier conocedor de los avatares

7 WeBer, Max, «Wissenschaft als Beruf 1917/1919, Politik als Beruf 1919», en Max Weber Gesamt Ausgabe, Abteilung I: Schriften und Reden, vol. 17 (Wolfgang J. Mommsen y Wolfgang Schluchter, editores, en colaboración con Birgitt Morgenbrod), Tübingen, J.C.B. Mohr (Paul Siebeck), 1992. En la nota número 50 de la página 14 de este volumen encontramos una referencia directa a Thomas Mann, que recogemos a continuación: A la contraposición, tan usual en la época, entre cultura alemana y civilización occidental, entre el espiritu (Seele) alemán y el intelecto (Intelekt) occidental, entre la gravedad (Tiefe) alemana y la ligereza (Oberflächlichkeit) occidental, entre la música y la (vacua) literatura, a esta distinción le ha proporcionado posteriormente Thomas Mann una expresión clásica. La nota nos recuerda además cómo las Consideraciones de un apolítico, antes de aparecer íntegras en 1918, fueron publicadas fragmentariamente desde dos años antes en diversos periódicos y revistas, entre ellos, las Münchner Neuesten Nachrichten, un medio de publicación igualmente apreciado por Max Weber. Las afinidades entre Mann y Weber encuentran un curioso terreno de manifestación en aquel punto de sus respectivas obras en que se reflejan las tensas relaciones intelectuales en el interior de sus propias familias: Thomas Mann incluyó a su hermano Heinrich bajo la categoría de Literatos de Civilización, y aún se puede sospechar que la expresión fuera creada ad hoc para responder intelectualmente a su hermano por su panegírica actitud frente a la república francesa, Max Weber, por su parte, arbitró el concepto de Erlebnisliteraten (Literatos de la vivencia) para mentar a su hermano Alfred, sobre el que volvemos en la siguiente nota. 
literarios del siglo XX acerca de la relevancia del término encantamiento, raro sería que el nombre de Thomas Mann no saliera a la palestra y su Zauberberg (Montaña encantada) no sirviera como ejemplo. Esto lo descubriría cualquier mirada mínimamente avisada y podría funcionar como punto de partida legítimo para cualquier investigación sobre ambos autores. El científico-profeta del desencantamiento y el literatomago del encantamiento, coetáneos, herederos de un mismo pasado sociocultural y protagonistas en el agitado mundo de la creación artística y científica alemana de las dos primeras décadas del siglo, trabajaron en las mismas fechas (Los Buddenbrook y La ética protestante y el espíritu del capitalismo se publicaron ambos en 1901), en ocasiones sobre motivos idénticos y casi siempre animados por un mismo impulso teórico, ahora que empleando cada cual herramientas de investigación y medios de expresión nítidamente diferenciados. Es evidente que las diferencias entre ambos pensadores quedarían pobremente explicadas si las refiriésemos exclusivamente a lo metodológico y no es menos verdad que ambos se cuidaron, con cierto escrúpulo intelectual, en conservarse en paralelo frente al otro, salvando cortésmente las distancias hasta en el terreno de lo personal ${ }^{8}$.

8 De hecho, sus escasos encuentros personales tienen lugar en relajadas reuniones mundanas, por ejemplo, a los cafés en la celebración de la boda de Eva y Klaus Hauptmann, el 9 de noviembre de 1919, o, también de sobremesa, en la reunión del 28 de diciembre del mismo año en casa del Consejero de Justicia Max Bernstein, en que, departiendo acerca de temas diversos, Weber polemizó brillantemente contra las tesis de Oswald Spengler. Es especialmente relevante la entrada del diario de Thomas Mann con fecha de 21-1-1920. En ella Mann da cuenta de una noticia que le llega a través de su hija Erika: Max Weber ha hablado contra Arco en la universidad de Munich, siendo abucheado escandalosamente por los alumnos. Se requirió incluso la presencia del rector. La convicción nacional-antirevolucionaria de los estudiantes me conforta profundamente, dice Thomas Mann al oír la noticia. Téngase en cuenta que el polémico trasfondo de este «desencuentro» entre Mann y Weber lo constituye la figura del Conde Anton de Arco auf Valley (1897-1945), teniente de la reserva, miembro de la hermandad Katholische Bayerische Studenten (estudiantes bávaros católicos), que disparó el 21.2.1919, en plena calle, al primer ministro (Ministerpräsident) Kurt Eisner (activista en consejos de trabajadores, Eisner fue quien estableció las bases para el establecimiento de la república del estado libre de Baviera el 8-11-1918, también ejerció como escritor, crítico teatral, etc.), cuando éste iba camino de la sesión de apertura del recién electo parlamento regional, con la intención precisamente de presentar su dimisión ante una cámara en la que su partido, el Partido Socialdemócrata Independiente, sólo había conseguido 3 de los 180 escaños en las elecciones de enero de ese mismo año. Las palabras escritas en el diario de Mann con fecha de 22-6-20 son tambien sintomáticas de la frialdad y distancia que mediaron entre Mann y Max Weber: al aire de una reseña de una reunión entre amigos, escribe Mann, Charla en torno al libro de M. sobre Bismarck y «Fiorenza», sobre el profesar Max Weber, muerto muy joven. Buen vino, un gran Mosela, chispeante. Curiosamente, la relación con el hermano de Max Weber, Alfred, fue más estrecha. Alfred Weber (1868-1958), fue profesor en Heidelberg desde 1907, donde 
De todos modos este trabajo no persigue un estudio comparativo de Weber y Mann. Y tampoco es nuestra intención polemizar acerca de la supuesta Buddenbrookización del primero ${ }^{9}$ o la posible Weberización de la novela del segundo sino seguir el destino literario del personaje de Hanno Buddenbrook a la luz de una hipótesis que remite a motivos fundamentales en la investigación weberiana. La hipótesis, inevitablemente ramificada en otras de menor alcance, podría resumirse del modo siguiente: entenderemos por vocación un modo de ascetismo orientado a la justificación de la existencia y dirigido a la constitución y modelado de un nuevo yo que se moviliza en orden a un valor último ${ }^{10}$; la obra de Thomas Mann pone en escena un relevo del ámbito de intervención humana sujeto a la vocación: éste se desplaza de la esfera del tráfico comercial a la esfera del arte, y, sustantivamente, de la música.

Thomas Mann le conoció personalmente en 1921. Alfred fue el autor de obras que Mann cita a menudo en sus diarios, aunque le merecieran juicios dispares, entre ellas: Die Krise des modernen Staatsgedankens, Kulturgeschichte als Kultursoziologie, Abschied von der bisherigen Geschichte y Religion und Kultur. Como dato anecdótico diremos también que la relación entre los Weber y los Mann continuó en la siguiente generación. Efectivamente, Max Weber-Schäfer, estudiante de física en los primeros treinta, era hijo del matrimonio formado por un arquitecto caído en la primera Guerra Mundial y la hermana de Max y Alfred Weber. El joven Max fue adoptado por su homónimo, y tío, Max Weber. Pues bien, el hijo de Thomas Mann, Golo, contó siempre al sobrino protegido de Weber entre sus más íntimas amistades Heidelbergensis. Véanse MANn, Thomas, Tagebücher, Franfurt am Main, S. Fischer, 1977-95, sobre Max Weber, especialmente el vol. Tagebücher 1918-1921, Frankfurt am Main, Fischer, 1979, pp. 57, 259, 317, 352, 370, 448.

9 Tesis que defendió Georg Lukács, dejándose seducir quizás por la literalidad de algunos pasajes de las Consideraciones de un apolítico, en especial éste que aquí se recoge: Atribuyo alguna importancia a la constatación de que he sentido e inventado completamente por iniciativa propia, sin lectura alguna, por comprensión directa, la idea de que el hombre de trabajo capitalista moderno, el «burgeois» con su «idea ascética» del deber profesional, es una criatura de la ética protestante, del puritanismo y del calvinismo, y sólo a posteriori, poco tiempo atrás, he advertido que esa misma idea había sido simultáneamente pensada y expresada por pensadores eruditos. Max Weber en Heidelberg, y tras él Ernst Troeltsch, trataron acerca de "la ética protestante y el espíritu del capitalismo», y esta idea se halla llevada a su mayor expresión en la obra «Der Bourgeois», de Werner Sombart, aparecida en 1913, la cual interpreta al empresario capitalista como síntesis del héroe, del comerciante y del burgués. Tiene razón en sumo grado, cosa que se desprende del hecho de que yo había plasmado su teoría doce años antes de que él la formulase, en mi carácter de novelista; ello suponiendo que la figura de Thomas Buddenbrook, la encarnación anticipatoria de su hipótesis, no haya tenido influencia alguna sobre el pensamiento de Sombart. Ver Mann, Thomas, Consideraciones de un apolítico, Barcelona, Grijalbo, 1978, pp. 164-65.

10 Esta definición está inspirada en la obra de Goldman, Harvey, Max Weber and Thomas Mann. Calling and the Shaping of the Self, University of California Press, BerkeleyLos Angeles-Londres, 1988. Se trata de una referencia indiscutible para el tema que nos ocupa, por lo que volveremos sobre ella a lo largo de nuestro trabajo. En adelante citada como GOLDMAN, número de página. 
Hanno Buddenbrook representa la fase primordial de ese relevo, de igual manera que Adrián Leverkühn habrá de encarnar medio siglo más tarde su fase terminal. La existencia del primero supone el anuncio de la definitiva transfiguración de la esfera profesional en que se manifiesta la vocación, transfiguración operada por el debilitamiento progresivo de la respuesta personal de sus antecesores a la vocación comercial que les interpelaba (por este motivo, la figura de Hanno será la protagonista de nuestro discurso, pero de un modo descentrado ya que el estudio de la personalidad de sus ancestros y, principalmente, de la de su padre el senador Thomas Buddenbrook, nos aportará tanto o más sobre el último varón de la familia que el tratamiento directo de su papel en la novela). Ocurre, sin embargo, que la inclinación musical del joven Hanno es aún antes el síntoma postrero de la ineluctable agonía de la saga de los Buddenbrook que una sólida predisposición a responder personal y adecuadamente a la vocación de la música. La muerte del adolescente contraviene exactamente la idea religiosa del sacrificio: en lugar de ofrecer su vida en reconocimiento de un Dios, su desaparición certifica que la estirpe que lo alumbró se ha alejado sin remedio de la divinidad.

Adrián Leverkühn es el representante terminal de aquel relevo. Su camino no contempla retorno posible: él habrá de responder a la vocación musical bajo las diabólicas condiciones que implica su calidad de moderno Fausto. El personaje de Leverkühn nos habrá de ocupar, sin embargo, en un trabajo posterior pues excede con mucho los límites del presente una investigación que intente mostrar cómo aquellas condiciones (propias de los manejos de un Mefistófeles al que ya no concierne la optimista concepción goethiana de la Providencia) revelan profundas concomitancias entre el destino de Leverkühn y la experiencia ética apoyada en los fundamentos religiosos que animaban a la ascesis profesional protestante, tal como es estudiada por Weber en sus diversas manifestaciones. Concomitancias que, sin embargo, habrán de ser interpretadas casi siempre «en negativo», sensibles como son a un tiempo, el siglo XX, profundamente desespiritualizado, en el que el desenvolvimiento profesional se ha descargado de cualquier interés ultraterreno de salvación, y del que también podría decirse que tiene el corazón seco.

\section{HANNO BUDDENBROOK}

Lübeck, lugar de nacimiento de Thomas Mann, localización sin nombre en la novela Los Buddenbrook, fue una de esas ciudades norteuropeas sede de las virtudes ascéticas de una burguesía dedicada al lucro racional. La saga de Los Buddenbrook explota literariamente el 
modelado específicamente urbano de las virtudes y su constitución característicamente burguesa en el seno del desenvolvimiento profesional. El siglo de los Buddenbrook es el XIX pero, aunque el tiempo narrado (Erzählte Zeit) ${ }^{11}$ alcance desde 1835 (comienzo de la narración) hasta 1877 (muerte del joven Hanno), sus raíces temporales hay que buscarlas en la segunda mitad del siglo XVIII, concretamente en 1768, año en que la firma comercial de la familia fue fundada por el padre del viejo Johann Buddenbrook. Sin embargo, no está de más atender a la genealogía, escrupulosamente delineada en el diario familiar, que refería mucho más atrás, hasta el siglo XVI, tiempo en que echó a andar la estirpe de los Buddenbrook. Resulta difícil creer que la ancestral indicación acerca del origen no obedezca más que a la casualidad: a fines del siglo XVI, un Buddenbrook, el primero que registran las crónicas... No puede ser casualidad que aquel siglo fuera el de la expansión transoceánica del comercio, el tiempo en que el grano comenzó a importarse a gran escala desde el Báltico hasta los Países Bajos y, desde allí, al resto de Europa, en que las asociaciones temporales como forma de organización primordial entre comerciantes dejaron expedito el camino a las grandes empresas creadas por el Estado pero poseídas y gestionadas por manos privadas, el siglo en que la Liga Hanseática comenzó a tambalearse debido a las crecientes fricciones con Inglaterra y se «dispuso» a sobrevivir a duras penas dos hechos traumáticos inminentes: la Guerra de los Treinta Años y la sensible merma en sus potencias al quedar exclusivamente formada por las ciudades de Lübeck, Bremen y Hamburgo. El siglo del primer Buddenbrook es, también y sobre todo, el siglo de Lutero y de Calvino. El siglo de la reforma protestante.

No sería descabellado afirmar que el siglo XVI es el telón de fondo histórico contra el que se recortan en última instancia las acciones y los pensamientos de todos los protagonistas de la saga. Mann se cuida de no desviar la atención del lector hacia ese contexto remoto y se limita a dar en una pincelada muy leve lo que bien pudiera interpretarse como el terreno en que crece la raíz más profunda de la conciencia religiosa y profesional de todos sus personajes. De todas formas, el lector de Los Buddenbrook tiene al ultimar la novela la sensación de que el universo temporal recorrido por su imaginación es más vasto de lo que le indica la literalidad de las fechas a que se sujeta la acción novelesca. ¿De 1835

11 La distinción entre Erzählzeit (tiempo narrativo) y erzählte Zeit (tiempo narrado) es imprescindible para cualquier hermenéutica literaria. El control sobre los rendimientos dramáticos y filosóficos del empleo literario de esta distinción es una de las estrategias de que se vale Mann, con plena consciencia acerca de los medios y vasta penetración de sus fines posibles, para sostener su monumental edificio novelesco. 
a 1877?: el lector duda entre remitir esa sensación de cósmica vastedad temporal ya a la fatalidad, a cuya luz extraordinaria son expuestos, con un dramático sentido de la acumulación, sucesos que, bien mirados, son perfectamente ordinarios, ya al poder mitificador de la narrativa de Mann, poder por el cual la travesía vital de las cuatro generaciones protagonistas de la novela cobra el espesor temporal propio de los relatos míticos no obstante la ineludible contextualización histórica del relato y la inalienable densidad psicológica de cada uno de los personajes.

Los Buddenbrook provoca en el lector un vértigo que es efecto específico de la ficción artística: el trastorno del sentido del equilibrio temporal. El impacto que genera el decurso familiar no es traducible recurriendo a la fraseología de la común experiencia y sabiduría del tiempo ni puede ser vertido a la misma conciencia temporal que nos sirve para discriminar entre hechos según la lógica causa/efecto. Los Buddenbrook tiene mucho de Cosmogonía porque es literatura preocupada del nacimiento y, sobre todo, evolución de un universo familiar y sociocultural. Sin embargo, difícilmente podrá interpretarse la novela como un mito del origen. El tiempo que transcurre desde aquel remoto siglo XVI hasta 1835, fecha en que la narración principia, se constituye en un pasado relativamente manso y amable, en todo caso escasamente problemático, frente al que la memoria de los Buddenbrook del XIX reacciona con naturalidad paulino-luterana: así es lo que así hubo de ser.

En cambio, estas cuatro décadas, objeto de atención de la diégesis, convulsionan los recuerdos, polemizan con un pasado erigido en juez mudo. Son cuatro décadas en que la personalidad de alguno de los miembros principales de la saga se abisma, como veremos, ante el peso de lo ordinario: incapaz de arrostrarlo siente cómo la confusión, el abatimiento, la duda, y una dolorosa entrega a la contemplación ocupan el lugar en que debían mandar la lucidez, la bienandanza, la claridad y el confortador impulso a la acción.

Los Buddenbrook es en realidad un moderno mito escatológico, sensible al ineluctable avance de las fuerzas oscuras, la novela es un relato de la entrada de la muerte en el mundo. Cuando la muerte desvía el curso preestablecido de los acontecimientos y liquida las expectativas de vida futura sembrando duda e inestabilidad, entonces, la muerte no concierne ya naturalmente al tiempo de la estirpe sino para darla fin absolutamente. Los mitos del fin del mundo, productos habituales de tradiciones urbanas, cuentan cómo la muerte finalmente se resiste a dejarse enrasar con el orden burgués, cómo rehúye todo afán de ordenación y asimilación ritual: ya no puntúa el trasiego generacional ni consagra traspaso ninguno de bienes y poderes sino que supone la intervención de un ser divino moral que destruye su propia creación. 
La muerte entra en el mundo llamada por un accidente, por el olvido de una enseñanza que instruía decisivamente acerca del orden humano o por el exceso de los límites del conocimiento. Todos estos motivos están presentes en Los Buddenbrook. Ahora bien, están imbricados con el motivo central de la vocación. Estudiaremos a continuación cómo el mito del fin se articula a partir de las diferentes respuestas personales que las sucesivas generaciones dan a la vocación comercial y de qué manera Mann asocia la entrada de la muerte con la irrupción de la música en aquel universo extraño hasta entonces a tales veleidades artísticas. En realidad se trata de algo más que de una simple asociación. El joven Hanno, último varón de la estirpe, es el postrer protagonista del mito del fin y, por ello, el personaje cuya muerte cobra un mayor espesor simbólico. Su inclinación artística hacia la música, hija de la ascendencia femenina sobre su persona, refleja el quebranto de una voluntad huidiza incapaz de forjarse una personalidad bajo el sello de una vocación. En la música la muerte se anuncia aniquilando el tiempo de la saga: el desplazamiento de la esfera profesional a que interpela la vocación desde el ámbito comercial hasta el ámbito artístico se queda a las puertas de su realización, como un proceso abierto e inconcluso. La metamorfosis de la vocación se anuncia; pero su anuncio es insuficiente para detener el exterminio, antes al contrario, le allana el camino. Hanno es un ser imposible de ganar para la vida de los negocios, tampoco posee, en cambio, la fuerza que le faculte para responder personalmente a la vocación del arte musical. Su vida es un ofrecimiento a ese mito del fin del mundo para que éste pueda representar la ceremonia de clausura de uno de los ciclos de la vida: el que tenía por centro el apellido Buddenbrook. Examinemos todo este proceso con detalle.

\section{Los Buddenbrook y el espíritu del capitalismo: tres precisiones en torno a la afinidad entre los Buddenbrook y la investigación Weberiana}

Es fácil comunicar los universos de Thomas Mann y Max Weber por medio de dos palabras clave: capitalismo y protestantismo. Hay otras que alcanzan más lejos (propongo, por ejemplo, vocación, desencantamiento, secularización, contienda de los dioses, demonio... sobre alguna de las cuales volveremos en este trabajo); pero quizás ninguna de ellas aviva tan inmediatamente los resortes de la comparación: el título La ética protestante y el espíritu del capitalismo anuncia con claridad meridiana cuáles son los intereses de Weber, intereses a los que 
Los Buddenbrook consagra la figura del bourgeois, el moderno hombre de negocios cuya vida se ordena racionalmente al servicio del deber profesional. La novela de Mann enseña cómo se puede hablar de ascesis sólo en la medida en que aquel ordenamiento responde con la propia vida del individuo a la vocación del trabajo comercial. Aquí reside la semilla ética del nuevo espíritu del capitalismo que se asocia a la reforma protestante.

Sin embargo, esta vía de acceso a Weber desde Los Buddenbrook - y viceversa - dista mucho de estar libre de obstáculos y polémicas. Cuando el análisis del concepto espíritu del capitalismo se erige en guía de la comparación entre ambos autores, las mistificaciones amenazan cada página. Lo mismo podría decirse al respecto de la interpretación de aquel espíritu como criatura de determinadas sectas reformadas. Acerca de estos impulsos comparativos, en ocasiones ciegos, conviene hacer algunas precisiones.

a) Max Weber no afirma en ningún caso que el espíritu del capitalismo sea criatura de ciertas vivencias éticas propias de determinada religiosidad protestante. En realidad no adquiere más compromisos que los derivados de investigar de qué modo y hasta qué punto determinadas experiencias éticas asociadas a diversas manifestaciones del protestantismo ascético influyeron en la constitución de un tal espíritu del capitalismo y demostraron una afinidad electiva ${ }^{12}$ con un nuevo modelo de desenvolvimiento profesional enfrentado al tradicionalismo (precapitalista en un sentido netamente capitalista) ${ }^{13}$.

12 La expresión técnicamente más ajustada a esta afinidad entre protestantismo/espíritu del capitalismo sería la de isomorfismo estructural.

13 Este matiz es en ocasiones olvidado por algunos intérpretes que, bien con intenciones críticas, bien con ánimo panegírico, imputan a Weber un compromiso mayor del que él tan nítidamente asume. Estas palabras polemizan a partes iguales con la interpretación marxista de la Reforma protestante y con la comprensión exclusivamente ética del capitalismo: Para ello conviene emanciparse de aquella concepción que pretendería explicar la Reforma como debida a una «necesidad de la evolución histórica», deduciéndola de determinadas transformaciones de orden económico. (...) Pero no menos absurdo sería defender la tesis doctrinaria según la cual el «espíritu capitalista» (...) sólo habría podido nacer por influencia de la Reforma, con lo que el capitalismo sería un producto de la misma. En primer término, hay formas importantes de economía capitalista que son notoriamente anteriores a la reforma, y ya este hecho desmiente aquella tesis. Lo que es menester señalar es si y hasta qué punto han participado influencias religiosas en los matices y la expansión cuantitativa de aquel «espíritu» sobre el mundo y qué aspectos concretos de la civilización capitalista se deben a ellas. WEBER, Max, La ética protestante y el espíritu del capitalismo, Barcelona, Península, 1995, pp. 106-7. El subrayado es nuestro. (En adelante citado como EP, número de página). 
b) Al intentar comunicar a Mann y Weber resulta peligroso leer acríticamente Los Buddenbrook y hacer de ella pasto favorable a las discriminaciones del Weber de La ética protestante y el espíritu del capitalismo. Es cierto que en ambas obras se investiga un relevo en la mentalidad que anima el desempeño profesional. En Los Buddenbrook ese relevo se nos da temporalmente a lo largo de distintas etapas, aunque es más fructífero su estudio por escenas: existe un relevo que afecta interiormente a la saga de los Buddenbrook y está escenificado por el salto de dos generaciones, desde el patriarca Johann hasta el senador Thomas Buddenbrook. Las palabras que el cónsul, padre de éste e hijo de aquél, dirige a su futuro sucesor ponen sobre el tapete todas sus dudas e inseguridades ante ese relevo en el interior de la razón social Johann Buddenbrook:

«Refiriéndome a tus planes comerciales para el futuro, hijo mío, me alegran por el vivo interés que revelan, aunque no coinciden con mi modo de ver. Partes del principio de que la exportación de los productos naturales del radio de tu ciudad natal, (..) deben constituir el más firme de los negocios de tu tierra y opinas que te puedes dedicar a ello sin contar las operaciones en depósito. En una época en que la competencia en esta rama de negocio era todavía mínima (y ha crecido considerablemente), también la puse en práctica como un experimento, (..) pero me convencí del peligroso carácter que representaban las operaciones de exportación y a causa de ello renuncié a mis proyectos en lo sucesivo, y desde entonces vengo ateniéndome al consejo que nos ha legado nuestro predecesor, el fundador de la casa: "Hijo mío, atiende con ánimo a los negocios durante el día, pero no hagas más que aquéllos que no puedan quitarte el sueño por la noche". Este lema es el que pienso seguir hasta el último día de mi vida, si bien tenga uno dudas, alguna vez, a la vista de gentes que, sin seguir estos principios, progresan, al menos en apariencia, más que nosotros.» ${ }^{14}$

Estas últimas palabras remiten a la otra escena en que acontece el relevo de mentalidad profesional: externamente a la saga Buddenbrook, entre ésta y los Hagenström. Un auténtico y desgarrador relevo de bienes y poderes simbolizado por el traspaso del domus, la gran mansión que erigiera Thomas Buddenbrook para certificar su patriciado. De hecho, los Hagenström son los representantes de esa burguesía rampante que a finales del siglo XIX se conducía en el mundo de los negocios a fuerza de golpes de astucia y considerable falta de escrúpulos. La emergencia de esta clase plebeya remozada por medio del dinero es interpretada en el universo de Los Buddenbrook como evidencia del irrefrenable proceso

14 Mann, Thomas, Los Buddenbrook, Barcelona, Plaza y Janés, 1996, pp. 183-84. (En adelante BuDD. y número de página ). 
de desespiritualización que convierte el mundo de los negocios en campo propicio para el aniquilamiento de toda prima ultraterrena de salvación. El auri sacra fames (anterior, de hecho, a la implantación del modelo económico capitalista) era ahora nueva y descaradamente vivificada por la inmoderación de la actividad profesional. «Desancorar» la organización del trabajo, arrancar del universo ético aquel impulso que llevaba a hacer del enriquecimiento una profesión... eso es lo que las últimas generaciones de Buddenbrook veían con ambiguos sentimientos: les dolía sospechar siquiera que los Hagenström pudieran estar haciendo justicia a los nuevos tiempos mejor que ellos mismos precisamente en aquella ciudad y en aquel ámbito sociocultural.

c) El relevo de «mentalidad profesional» en Los Buddenbrook puede ser enunciado con estas o parecidas palabras. Las consideraciones que realiza Max Weber acerca de la ética protestante arrojan sobre la novela de Mann una luz que descubre, sin embargo, ciertas ambigüedades que marcan las distancias entre la consistencia argumental del sociólogo y la hilaza dramática del poeta. Weber persigue aquella mentalidad de la que nació, como fenómeno de masas, el espíritu específicamente moderno del capitalismo ${ }^{15}$. Su discurso enfrenta este espíritu con el tradicionalismo económico. Tradicionalista es aquella mentalidad económica que se guía por el siguiente principio: ganar lo necesario para seguir viviendo, pura y simplemente, como siempre se ha vivido. Efectivamente, el nuevo espíritu descubre en tal criterio un obstáculo difícil de salvar. Lo que Weber observa con tino es cómo determinada fe religiosa predispone la más favorable coyuntura para la superación de la parsimonia y conservadurismo tradicionalista: cuando la capacidad de concentración del pensamiento se aúna con la actitud rigurosamente fundamental de sentirse obligado al trabajo ${ }^{16}$, cuando se da un estrecho maridaje entre el cálculo de la ganancia, un austero dominio de sí mismo y una moderación que acrecienta la capacidad de rendimiento en el trabajo, entonces, es prácticamente posible la consideración del trabajo como fin en sí como "profesión» que es lo que el capitalismo exige ${ }^{17}$.

Resulta tentador aplicar este conflicto entre tradicionalismo/espíritu del capitalismo a aquel relevo de que se ocupa Los Buddenbrook. Sin embargo, hay que ser escrupulosos con la historia. Los Buddenbrook presenta en un estado muy avanzado, terminal estaríamos por decir, aquel proceso de la historia económica específicamente occidental que

\footnotetext{
15 Ver EP, 56 ss.

16 Cotéjese esta relación de condiciones favorables al espíritu del capitalismo con EP, 62.

17 Ibidem.
} 
llevó al éxito el nuevo espíritu del capitalismo. Recordemos que la saga de los Buddenbrook concluye, narrativa y «físicamente», el año 1877. Reviste, por lo tanto, mayor trascendencia de la que aparenta la siguiente cita de La ética protestante...

«(...) por lo general, en los albores de la nueva época, no fueron única ni siquiera preponderantemente los empresarios capitalistas del patriciado comercial, sino más bien las capas más audaces de la clase media industrial las representantes de aquella mentalidad que llamamos "espíritu del capitalismo". Y en el siglo XIX (el siglo de los Buddenbrook), sus representantes clásicos no son los nobles gentlemen de Liverpool o de Hamburgo (ciudad hermana de Lübeck, y de la no nombrada de la novela de Mann) con el patrimonio comercial heredado de sus antepasados, sino los parvenus de Manchester, de Renania y de Westfalia, procedentes de las más modestas capas sociales. Pero ya en el siglo XVI (el siglo del primer Buddenbrook) ocurría lo propio: las nuevas industrias entonces nacidas fueron creadas por los parvenus.» ${ }^{18}$

Efectivamente, lo que interesa averiguar es hasta qué punto el desenvolvimiento profesional de las diferentes generaciones de Buddenbrooks permite discriminar entre forma de empresa capitalista y espíritu capitalista. Es evidente que la actividad económica de la firma Johann Buddenbrook sólo puede ser ejercida bajo la forma de empresa capitalista, pero, ¿el espíritu que anima su dirección ha abandonado completamente la parsimonia tradicionalista? Aquel sastre de Rostock, que, como arrojado ancestro, es mentado a lo largo de la novela por alguno de sus modernos epígonos, puede ser considerado como uno de esos parvenus de que habla Weber. Los Buddenbrook protagonistas de la novela son patricios del siglo XIX, nobles gentlemen, miembros de la aristocracia del capital, que, frente al empuje de la nueva burguesía sin escrúpulos, arribista y desencantada, representada por los Hagenström, se sienten igual de desplazados que se debieron de sentir los nobles feudales, aristócratas de la tierra y de la sangre, ante el arrojo de aquel primer Buddenbrook del siglo XVI.

Es cierto que el lema que grabó el anciano Buddenbrook en el frontispicio del diario generacional: atiende con ánimo a los negocios durante el día, pero no hagas más que aquellos que no puedan quitarte el sueño por la noche, es fácilmente interpretable como signo del conservadurismo latente en la actividad económica de la saga. Sin embargo, esto no basta para tachar de tradicionalista a aquella actividad. En realidad, se incurriría

18 EP, pp. 64-65. 
en un error si se quisiera interpretar el conflicto Buddenbrook/Hagenström como ejemplo del derrumbe de la vieja guardia tradicionalista ante el empuje de las nuevas fuerzas económicas animadas por el espíritu del capitalismo. Thomas Mann dibuja un mapa económico algo más denso y complejo. Johann Buddenbrook, el miembro más anciano de la familia de entre los que aparecen en la novela encarna, de hecho, y con inusitado vigor, el nuevo espíritu del capitalismo. El encarna esas cualidades éticas que son específicas del nuevo espíritu: no se trata de una forma de organización empresarial, sino de un ethos; no tiene que ver con la osadía y la falta de escrúpulos sino con un sentido del riesgo en realidad cercano a la perseverancia; no es propio de naturalezas aventureras antes bien sobrias, moderadas, prudentes. Todo esto significa entrega plena y devota a unos principios rígidamente burgueses ${ }^{19}$.

Mann y Weber son sensibles a un mismo proceso de decadencia, sus talentos no se ordenan con tanta fuerza e inspiración al análisis de la implosión o derrumbe de la parsimonia tradicionalista como al estudio del desgarrador proceso que supuso el declive, la secularización y el desencantamiento de aquel espíritu que libró batalla contra el conservadurismo económico. De hecho, el cabeza de familia de los Hagenström dista de ser el tipo ideal de empresario capitalista que Weber dibujó al trazo en este pasaje de su obra La ética protestante...

«los que van a parar al puerto de la riqueza fideicomisaria y de la nobleza otorgada, con hijos cuya conducta en la Universidad o en el Ejército trata de hacer olvidar su origen, como frecuentemente ha ocurrido en tantas familias de advenedizos del capitalismo alemán, constituyen un producto epigonal de decadencia. El "tipo ideal" de empresario capitalista (...) nada tiene que ver con este tipo vulgar o afinado de ricachón. Aquél, aborrece la ostentación, el lujo inútil y el goce consciente de su poder; le repugna aceptar los signos externos del respeto social de que disfruta, porque le son incómodos. Su comportamiento presenta más bien rasgos ascéticos (...). Y, sobre todo, no es raro sino muy frecuente, hallar en él un grado de modestia mucho más sincera que la reserva tan prudentemente recomendada por Benjamín Franklin. "Nada" de su riqueza lo tiene para su persona; sólo posee el sentimiento irracional de "cumplir buenamente en su profesión".»

Olvidémonos, si se quiere, de establecer nítidas diferencias entre Buddenbrook y Hagenström por lo que se refiere a la aceptación de los signos externos del respeto social de que disfrutan. También los Buddenbrook se

19 Ver EP, pp. 69-70. 
desviven por promover a uno de sus miembros entre la oligarquía senatorial de la ciudad y confían en que el reclutamiento plutocrático de las capas políticamente dirigentes de su ciudad les favorezca personalmente ${ }^{20}$. Es evidente que no se trata tan sólo de que el acceso a la clase políticamente dominante les permita utilizar su dominación política para sus intereses económicos privados, hay también algo acaso más importante para ellos: en la medida en que los protagonistas de Los Buddenbrook interpretan la vida política como reflejo del estatuto socioeconómico, están cifrando todas sus esperanzas de supervivencia en su incorporación a la plutocracia ciudadana. No quieren reconocer que lo que políticamente fue una vez reflejo adecuado de su poder económico, un día se convierte en un espejismo, en el brillo de una estrella ya extinta. El poder político se transforma en una ilusión incapaz de sustituir a la influencia del dinero.

Sin duda, la aceptación de los signos externos de respetabilidad social tiene mucho que ver con la idea de legitimidad del capital. Aquí las diferencias entre uno y otro origen, entre uno y otro ethos, se afinan. En términos particularmente relevantes se dirige Thomas Buddenbrook a su hermana Tony (muy interesantemente caracterizada como una mujer de la que se podría decir que era de una grosera altivez si no se condujera en realidad en atención a una conciencia de clase desenvuelta en un patológico infantilismo femenino: ha pagado, desgracia tras desgracia, con su propia vida el importe afectivo del declive de la familia pero se niega a ver en ello señal indicativa de nada que no sea una irritante amenaza de advenedizos; ella es la auténtica protagonista femenina de la novela y contrapunto neurótico de la moderación y discreción, aun en sus acepciones más hipócritas, que rige el universo masculino) se dirige a su hermana, decimos, en estos términos acerca del interés de los Hagenström por su nueva y espléndida mansión:

«Han ido encumbrándose, la familia crece, se han emparentado con los Möllendorf, y en prestigio y riquezas están al nivel de los primeros. Pero les falta algo, algo exterior, algo de que han venido careciendo hasta el presente, supliéndolo a fuerza de aplomo y despreocupación... Les falta la consagración histórica, la legítima, por decirlo así... Ahora parece que le han tomado gusto y quieren procurársela; por ello empiezan adquiriendo una casa como ésta...»

Y sigue con unas palabras que afectan directamente a nuestros intereses y dan con la clave de aquel encantamiento o consagración que

20 Véase la citada conferencia Política como vocación, traducida en WeBER, Max, El político y el científico, Madrid, Alianza, 1996, pp. 98-9. 
media entre el orden económico de actividad material y el orden ético de salvación espiritual:

« $i \mathrm{Oh}$, puedes estar tranquila, el cónsul (en referencia al señor $\mathrm{Ha}$ genström) procurará conservar aquí todo lo posible, no derribar nada; incluso dejará sobre la puerta el Dominus Providebit, a pesar de que, en justicia, es preciso reconocer que no ha sido el Señor, sino él sólo quien ha llevado a la razón social "Strunck \& Hagenström" a sus actuales alturas...!»

En este caso la caprichosa altivez de Tony, su desfachatado escrúpulo de casta más que de clase, es más sensible al curso del destino familiar: poner el domus en otras manos, y precisamente en aquéllas, no es ninguna extraña ironía de la suerte, como dice Thomas; se trata de que los Buddenbrook han fracasado definitivamente y se retiran, mientras los Hagenström ocupan su lugar a son de bombo y platillos. Y lo que se retira es, en realidad aquella moderación y fortaleza de ánimo con que se revistió el fundador de la firma Johann Buddenbrook, acosada y debilitada por mil fantasmas interiores. Los Hagenström no suponen una amenaza mayor que la pérdida de consistencia moral, el progresivo ensimismamiento y el sucesivo abandono a un talante contemplativo y reflexivo de que hacen gala los epígonos de la saga de los Buddenbrook. Todo ello, además, en el tiempo (fines del siglo XIX) en que se había cortado definitivamente el cordón umbilical que unía hasta entonces el comportamiento práctico «crematístico» y una determinada «concepción unitaria del mundo», es decir, la época en que el capitalismo empezó a funcionar como una fuerza ciega que no necesitaba de asideros religiosos para imponerse.

Es verdad que la misma fortuna de la saga había sido fruto de ese proceso que convirtió al capitalismo en una fuerza profesional emancipada de las viejas formas de constitución político-económica y religiosa derribadas por el Estado moderno; pero no es menos cierto que para la formación del espíritu del capitalismo que tuvo en el anciano Johann Buddenbrook uno de sus ejemplos revestía una importancia sustancialmente menor el impulso constante de sus representantes hacia su propio enriquecimiento que el hecho de que tal enriquecimiento fuese integrado en la categoría de profesión. Esta obligación funcionó como base ética de la conducta del empresario moderno. Y en la medida en que la conducta se obligaba a ese ethos no podemos hablar de una emancipación religiosa del capitalismo (a menos que se confundan emancipación religiosa y emancipación eclesial), no por lo menos en el sentido en que sí podemos hacerlo al respecto de individuos como el cónsul 
Hagenström cuya conducta parece convulsionada por todos los tics económicos de la desespiritualización post-moderna.

\section{Los Buddenbrook y Lutero}

Lo que distingue la trayectoria de los Buddenbrook de la carrera profesional de los Hagenström es la misma distinción que cabría hacer entre los conceptos de destino y avatar. Si hemos puesto algún empeño en recorrer estas diferencias ha sido para revelar cómo, para los Buddenbrook, detrás de la manifestación de una actividad económica capitalista operaba un sentimiento irracional de obligación a una profesión, pues la racionalidad de las formas de vida y pensamiento propias de la saga capitalista se desenvuelve en una abnegación hacia el trabajo profesional que, desde el punto de vista del interés eudemonístico ${ }^{21}$, revela un elemento irracional. Lo que analiza Weber y explota con tan demoledor sentido dramático Mann es precisamente esta cara oculta del término profesión. Ambos trabajan como genealogistas del concepto profesión y hallan en la raíz de la palabra misma una pista decisiva: es evidente que en la palabra alemana "profesión» (Beruf), como quizá más claramente aún en la inglesa calling, hay cuando menos una reminiscencia religiosa: la idea de una misión impuesta por Dios ${ }^{22}$.

Se puede afirmar que la revelación de un sentido nuevo para el concepto de profesión fue hija de la Reforma. Lo cual nos vuelve a situar en el siglo XVI: con él nace una estimación inédita del trabajo cotidiano en el mundo. Como dice Weber, lo propio y específico de la Reforma, en contraste con la concepción católica, es el haber acentuado el matiz ético y aumentado la prima religiosa concedida al trabajo en el mundo, racionalizado en "profesión»" 23 . No podemos entrar aquí a debatir al detalle las aportaciones personales de Lutero pero, en la medida en que el universo moral de Los Buddenbrook está impregnado de Luteranismo, explícitamente en sus protagonistas femeninos, que, al fin y a la postre, son quienes conservan ritualmente la llama de la fe en el interior del $d o$ mus, sí conviene destacar cómo fue precisamente la valoración ética de la vida profesional una de las aportaciones decisivas de la Reforma en general y de Lutero en particular.

No nos interesa tanto analizar las vacilaciones primeras de Lutero, su fuerte anclaje en el escolasticismo, su posterior revalorización del

\footnotetext{
21 Ver EP, p. 80.

22 Ibid., p. 81.

23 Ibid., p. 96.
} 
trabajo profesional en el mundo o el afianzamiento de la idea de que el desempeño de una determinada profesión constituye como un mandamiento que Dios dirige a cada cual, obligándole a perseverar en la situación en que se halla colocado por la divina providencia. Para el análisis de Los Buddenbrooks, y, en especial, para comprender ese gran arco del tiempo que vence en la figura de Hanno, es fuente de polémica la acentuación luterana del elemento providencial que lleva a derivar directamente el orden objetivo histórico, en que se encuentra por designio divino el individuo, de la voluntad de Dios. Como indica Weber, esta acentuación del carácter providencialista de la existencia histórica conduce irremisiblemente a una concepción de tipo tradicionalista análoga a la idea del destino: cada cual, vendría a defenderse, ha de sostenerse en su profesión y en el estado en que se halla pues tal es la voluntad de Dios. Voluntad, además, expresada de una vez y para siempre:

«resulta así que el tradicionalismo económico, que al principio es resultado de la indiferencia paulina, es fruto más tarde de la creencia cada vez más fuerte en la predestinación, que identifica la obediencia incondicional a los preceptos divinos y la incondicional resignación con el puesto en que cada cual se encuentra situado en el mundo. Lutero, pues, no llegó a basar en principios realmente nuevos o verdaderamente fundamentales su vinculación del trabajo profesional con las ideas religiosas.» ${ }^{24}$

Si el concepto de profesión conservó todavía en Lutero un carácter tradicionalista en tanto en cuanto profesión era aquello que el hombre ha de aceptar pues la providencia se lo envía, algo ante lo que hay que allanarse, y si el universo moral de Los Buddenbrooks participa del luteranismo, la pregunta que convendría hacer es en qué medida la conducta económica de la saga está animada por este protestantismo misional ${ }^{25}$.

24 EP, p. 99.

${ }^{25}$ En un estudio que resulta de gran utilidad para nuestros intereses, Michael Walzer analiza la idea puritana de convenio relacionándola con las dificultades que asaltaron a la mentalidad religiosa reformada a la hora de responder pertinentemente a la vocación ( $\mathrm{Ca}$ lling): a la «llamada» divina no se puede responder mediante una actitud de pasiva y pía aquiescencia; la in-vocación insta a que los hombres se pongan a sí mismos en servicio (Men must make themselves «serviceable»). Es decir, como nos recuerda Walzer, la idea puritana del convenio se cifra precisamente en el recíproco entendimiento entre la intención (Willfulness) divina y la activa complacencia (Willingness) humana. Conforme a nuestra hipótesis de trabajo, la confrontación de las cuatro generaciones de Buddenbrook con la idea puritana del convenio resulta mucho más estimulante y significativa que una interpretación de sus sucesivas y diferenciadas respuestas a la vocación comercial bajo la luz del allanamiento luterano. Véase WALzER, Michael, The revolution of the saints. A study in the origins of radical politics, Harvard University Press, Cambridge, Massachusetts, 1965, p. 167. 
Efectivamente, lo que nos interesa no es examinar la religiosidad de la familia, ni siquiera entrar a valorar sus manifestaciones internas como paradójicos síntomas de la pérdida de la fortaleza operativa y eficiencia práctica (no en vano todas sus manifestaciones rituales - ceremonias, reuniones y oraciones- son conducidas por los miembros femeninos de la estirpe, e incluso la novela comienza con la joven Tony recitando a trancas y barrancas el catecismo mientras su abuelo ríe de buena gana sus errores), lo que nos interesa es destacar lo que había de nuevo en el Luteranismo por lo que concierne al orden ético: la desaparición de los específicos deberes ascéticos allende los deberes a cumplir en el mundo.

Esta comprensión inmanente de la ascesis y su remite al orden económico de intervención humana por medio de la idea de profesión, nos sirve como punto de partida para nuestro análisis de la vocación. Por lo que respecta a Los Buddenbrooks, no conviene comprometer las bases psicológicas que animan el desenvolvimiento económico de las distintas generaciones de la familia con las concepciones más ortodoxas de la iglesia luterana, pues, como demostró Max Weber, sus concepciones despreciaban la tendencia a la autodisciplina ascética por ver en ella una santificación de las obras, y distaron mucho, en todo caso, de promover los cimientos firmes de una ética racional de la profesión tal y como podemos hallarla en Los Buddenbrook. Con esto queremos decir que, aunque el universo religioso de la novela está histórica y culturalmente impregnado de protestantismo (Odio el catolicismo y ya sabéis que no lo disimulo... dice Tony, tras una de sus amargas excursiones matrimoniales a $\mathrm{Mu}-$ nich), no es Lutero la figura que representa el ascendiente espiritual de la saga.

Era, innegablemente, una respetable y conspicua personalidad local, cuyo prestigio se debía ante todo a la tolerancia y al liberalismo de su carácter, virtudes nuevas que le ensalzaban a los ojos de muchos y le daban gran autoridad. El modo hábil y despreocupado en que ganaba el dinero y lo gastaba, era muy distinto de aquel delicado, paciente y regulado por inmutables principios tradicionales que seguían sus conciudadanos negociantes ${ }^{26}$, se dice acerca del cónsul Hagenström en Los Buddenbrook, y esto supone discriminar en el interior del edificio de la ficción entre tradición sociocultural y tradicionalismo económico. Supone aceptar la hipótesis de que la forma de organización profesional efectivamente animada

26 BudD., p. 417. 
por el nuevo espíritu del capitalismo no sólo se determina socialmente ante la historia sino que se constituye también en una cultura. Y este proceso de determinación sociocultural del espíritu del capitalismo permite hablar a Mann de una tradición económica allende el tradicionalismo económico tal y como lo hemos definido en este trabajo. Es la tradición económica comprendida en un sentido propiamente cultural y no el tradicionalismo económico lo que convulsiona la efervescencia de las nuevas virtudes de Hagenström. El anciano Johann Buddenbrook se había conducido ya con una liberalidad de talante y un relajamiento religioso que hacían de él uno de aquellos despreocupados epígonos de la ilustración que habían de reconducir todas sus fuerzas hacia la esfera de la profesión. Y si los designios del dios providente no se auscultaban tras cada uno de las empresas mundanas, sí pesaba sobre ellas un cierto carácter misional y, sobre todo, una fuerte valoración ética en la medida en que de ellas se hacía depender la justificación de la propia vida. Fue este impulso el que se agotó a las puertas del nacimiento de Hanno Buddenbrook.

\section{Los Buddenbrook y el concepto de «Beruf»}

Ya hemos observado cómo en Los Buddenbrook la palabra alemana Beruf está a la base de toda relación personal hacia el trabajo y cómo esta relación cimienta los procesos de identificación individual y cultural. Esto basta para desmarcar el universo de la novela de Mann de los conceptos al uso en las sociedades industrializadas contemporáneas, en las que el término Beruf se agota en el significado próximo de profesión: ocupación, oficio... Mann evoca, en cambio, las raíces subterráneas de la palabra y articula el complejo entramado de Los Buddenbrook en atención a las esencias religiosas de la palabra Beruf como innovación, llamada, nombramiento, designación... La consecuencia directa de esta búsqueda de las raíces religiosas del término podemos encontrarla en un modelo de personalidad que polemiza directamente con aquél que la juventud alemana de las dos primeras décadas del siglo XX pretendía forjarse al amor del menudeo de vivencias que afectaran directa y novedosamente al decurso existencial de cada sujeto. Frente a este modelo prolífico y disperso que hacía centro en la palabra vivencia (Erlebnis), Mann y Weber proponen otro bien distinto: para ambos, los procesos de forjamiento de una identidad personal, confrontados a una crisis de sentido social y cultural, sólo pueden constituirse 
por medio de la dominación del Yo y su movilización o puesta en servicio $^{27}$.

Como nos recuerda Harvey Goldman, la obra de Thomas Mann nos permite avanzar en la investigación del problema del estatuto del arte y de la identidad del artista si consideramos como una preocupación capital del autor no sólo el estudio de sus problemáticas relaciones respectivas con la vida sino la apropiación del concepto de vocación ${ }^{28}$. Thomas Mann esgrime el concepto de vocación como argumento de legitimación y fortificación del Yo del artista y cifra en el análisis de tal concepto todas sus esperanzas de crítica y de respuesta al ineluctable proceso de descomposición de un cierto sector de la burguesía alemana de la época que se rindió, exhausta y estéril, ante la naturaleza soldadesca de la vocación.

En nuestro análisis de Los Buddenbrook quisiéramos mostrar cómo el cese de la vocación mundana de una estirpe familiar burguesa favorece el afloramiento de una nueva sensibilidad, cómo en esta novela el arte es el fruto de un colapso y la música hija de una pérdida; cese, colapso y pérdida que, en la medida en que afectan radicalmente a la interpretación del mundo y de sí mismo, impiden que sus efectos artísticos adquieran otra naturaleza que la de síntoma o castigo, frustrando, como si se tratara de una condena, sus posibilidades de constituirse en una alternativa de vida. El brote de un alma artística sólo puede ser interpretado en Los Buddenbrook en la vecindad de este colapso de la vocación que afecta interiormente al mundo de una familia de Erwerbsmenschen (comerciantes).

Rainer Maria Rilke, a quien Mann siempre agradeció su favorable acogida de la novela, destaca el que Los Buddenbrook muestre la vida calma e inconsciente de una generación anterior y la precipitación nerviosa y autoexploratoria de sus descendientes... Para el autor de

27 También en este punto la obra de Michael Walzer resulta de gran ayuda: de manera esclarecedora investiga las virtudes auto-afirmativas que la religiosidad protestante asociaba al desempeño sistemático del trabajo. Los santos se distinguían del común de los mortales precisamente por su diligencia profesional: their industry revealed their saintliness (su trabajo revelaba su santidad). Efectivamente, se contemplaba aquí una sistemática e inflexible estrategia de dominación del Yo de la que se derivaban sustanciosos réditos sociales en forma de legitimación personal y, lo que era aún más importante, comunitaria: La vieja teoría católica de las buenas obras fue aquí transformada en la teoría protestante de la buena obra: la diferencia estriba no sólo en la cuestión de la eficacia sino, muy significativamente, en la cuestión de la naturaleza de la actividad requerida, nos dice Walzer y sus palabras alumbran la idea de personalidad que estaban ensayando Mann y Weber en sus respectivas obras. WALZER, Michael, Opus Cit., p. 211.

28 Goldman, pp. 4-5. 
«Elegías de Duino» gran parte del interés de la obra de Mann radica en que es mostrado con particular agudeza cómo la decadencia de la familia se manifiesta sobre todo en el hecho de que sus miembros individuales hayan cambiado la dirección de sus vidas: ya no resulta natural para ellos vivir.. de cara al mundo exterior; es decir, la tendencia a la introversión se hace cada vez más evidente ${ }^{29}$. Y, efectivamente, las palabras de Rilke se compadecen muy bien con aquel proceso de que también nos habla Mann en su ensayo Lübeck como forma de vida espiritual: el proceso de descomposición del burguesismo o «desburguesificación» (Entbürgerlichung), que es también el proceso de pérdida biológica de la eficiencia (Enttüchtung) por medio de la diferenciación y el afloramiento de una sensibilidad enfermiza y paralizadora ${ }^{30}$.

Con todo, el terreno sobre el que se desliza el desgarramiento de la saga tiene en Los Buddenbrook un carácter eminentemente religioso. Aquí reside, creemos, la fuerza con que impacta en el lector la novela y, también, su íntima comunión espiritual con Max Weber. El mismo ánimo entre profético y diagnóstico que late en las desoladas últimas páginas de La ética protestante... vibra también en Los Buddenbrook. Thomas Mann levanta acta del tránsito desde el escepticismo neoilustrado que bullía desenvueltamente en el comportamiento del anciano Johann Buddenbrook hasta el fanatismo beato de su hijo, y de éste a una nueva forma de escepticismo que ya ha dejado de ser reconfortante y nutricio, la del senador Thomas Buddenbrook quien, huyendo igualmente de la beatería del uno y de la cómoda superficialidad del otro, habíase contestado históricamente a las incógnitas planteadas por la inmortalidad, diciéndose que había vivido en sus progenitores y que seguiría viviendo en sus sucesores. Tal concepción no sólo estaba de acuerdo con su idea de familia, con su conciencia patricia y su tradicional piedad, sino que se apoyaba asimismo en su actividad, en su ambición y en todo el programa de su vida. Pero confrontado a la reali-

29 RILKE, Rainer Maria, «Thomas Mann's Buddenbrooks», en HatFiEld, Henry, edit., Thomas Mann. A Collection of Critical Essays, Englewood Cliffs N.J., Prentice-Hall, 1964, pp. 8-9.

30 Véase el ensayo «Lübeck als geistige Lebensform» en MANN, Thomas, Essays, Band 3: Ein Appell an die Vernunft 1926-1933, Fischer, Frankfurt am Main, 1994, pp. 16-38. El discurso de Mann en esta conferencia ante sus «conciudadanos» vuelve una y otra vez sobre Los Buddenbrook. En realidad la descripción de los puntos principales de todo este proceso de «desburguesificación» la pone Mann en boca de un lector de su novela: Cuán a menudo, por ejemplo en Suiza, en Holanda, en Dinamarca, he oído exclamar a gente joven: «este proceso de desburguesificación, de pérdida biológica de la eficiencia por medio de la diferenciación y la hipertrofia de la sensibilidad... exactamente como nos ocurrió a nosotros». Ver supra, p. 24. 
dad de su inminente aniquilación, Thomas, el padre de Hanno, no encuentra consuelo ni arrimo en este historicismo de corte biológico: $Y$, no obstante, ahora, bajo la próxima y segura pupila de la muerte, todo este sistema histórico se desvanecía, reduciéndose a la nada, y era incapaz de proporcionarle una sola hora de calma y de prepararle para el fin... ${ }^{31}$

\section{El anciano Johann Buddenbrook}

El abuelo de Thomas, el anciano Johann Buddenbrook, fue un deísta librepensador; acaso admitiera, sí, un Dios como autor de la naturaleza, pero en modo alguno la revelación y el culto externo y cualquier otro criterio sobrenatural del que se quisiera hacer depender la razón individual $^{32}$. Ríe, como dijimos, la transmisión del catecismo luterano de padres a hijos como si se tratara de superchería, y, en un pasaje especialmente esclarecedor, se enfrenta a su hijo por la forma como pretende remozar un descuidado jardín de su propiedad:

— «iPor Dios, papá! Disfruto mucho en verano, paseando entre aquellas malezas, y para mí perderían su encanto, si tan bella y libre naturaleza se viera, lastimosamente, arreglada con simetría...»

— «Pero cuando la libre naturaleza me pertenece, creo que tengo perfecto derecho a disponer de ella a mi antojo.» ${ }^{33}$

Se trata de uno de tantos pasajes en que la impronta del carácter del anciano Buddenbrook se hace notar contundentemente en sus palabras: frente al modelo mesopotámico de jardín como paraíso, es decir, como espacio simbólico en el que cohabitan los principios de la vida y de la muerte, el talante renacentista del patriarca parece convenir mucho mejor con la idea del jardín griego donde el elemento arquitectónico domina a la naturaleza virgen, salvaje. Y, efectivamente, el viejo Buddenbrook parece haberse forjado el carácter al amor de aquella racionalidad helena que proponía al hombre como medida de todas las cosas, y, más cercanamente, a la sombra de las conquistas de la Ilustración. Quisiera ver emancipados los esfuerzos cotidianos de las presiones sobrenaturales y

31 Budd., pp. 648-49.

32 Para la exposición de la respuesta personal de cada una de las generaciones de Buddenbroock a la vocación comercial tendremos en consideración el trabajo citado de Harvey Goldman, sobre todo GoLDMAN, pp. 65-85.

33 Ibid., p. 31. 
aún la educación de los jóvenes de toda mistificación científica que obstaculizara una sana disponibilidad hacia el trabajo.

\section{El Cónsul Johann Buddenbrook}

Homónimo de su padre, el cónsul Johann Buddenbrook había heredado de él un fuerte sentido del desempeño profesional, comprometiendo su vida al éxito de la empresa familiar. No obstante, en comparación con la mundana desenvoltura de su antecesor ${ }^{34}$, las cualidades que le movían en el comercio distaban de ser acendradas: aquella $p u$ reza burguesa, aquel inmaculado impulso hacia la acción se teñían ahora de fanático amor por el Salvador. La historia del linaje de los Buddenbrook se convierte con la figura del Cónsul Johann en la historia de una regresión espiritual. Más allá de los motivos que le llevan a defender tenazmente la unión fronteriza germana, el constitucionalismo francés y cualquier otra medida económica o política que favorezca la prosperidad de la vida práctica, su ánimo empresarial está marcado por la intimación de la idea escatológica de salvación en la idea terrena de profesión.

Es precisamente éste el personaje en que antes saltan a la vista las concomitancias con el ascetismo puritano del siglo XVII que describió Weber. En este sentido Harvey Goldman apunta certeramente hacia aquel proceso de regresión que mencionábamos cuando afirma que en él se hace nítidamente visible la santificación del trabajo y del deber, que señala el renacimiento de una mirada pre-ilustrada ${ }^{35}$. La mirada que proyecta el Cónsul Johann hacia el universo económico a que su vida se obliga no es la de quien ve en él la expresión que se compone bien con sus talentos o descubre la ocupación que conviene a sus inclinaciones «naturales». El comercio se convierte en el ámbito en que se hace efectiva la vocación en un sentido Calvinista: una interpelación u obligación que excede los límites y querencias de la naturaleza individual. La conciencia profesional del Cónsul Johann se constituye a partir de criterios que a su antecesor bien podrían parecerle sobrenaturales.

La vocación del Cónsul reviste un sentido ultramundano. Mann destaca no tanto lo que la vocación tiene de fuerza impelente hacia el trabajo

\footnotetext{
34 Una comparación detallada de las diferentes actitudes del anciano Johann y su hijo el Cónsul puede encontrarse en: NACHMAN, L.D. y Braverman, A.S., «Thomas Mann's Buddenbrooks: Bourgeois Society and the inner Life», en Germanic Review, 45, 1970, pp. 201-25.

35 Goldman, p. 66.
} 
como su condición de fuente para la disciplina del Yo. Para Johann Buddenbrook hijo, la vocación es la fuente de aquella fe que le lleva a interpretar todos sus éxitos como expresión de la voluntad divina. Esta fe, sin embargo, no es interpretada en Los Buddenbrook como principio fortificador de la acción humana. Es la misma fe que, conforme se van sucediendo los fracasos - algunos con auténtico escarnio del honor familiar, como el primer matrimonio de su hija Tony con el sospechoso y desalmado señor Grünlich, deseoso exclusivamente de satisfacer a sus acreedores con la dote de la hija del Cónsul Buddenbrook y condenado finalmente a la bancarrota-, conforme el germen de la incertidumbre ha inoculado la salud de la saga, convierte la hidalga mansión de la familia en centro de peregrinación de la espiritualidad tanto luterana como reformista, y favorece que sea considerada como seguro y hospitalario puerto para toda misión, interior o exterior ${ }^{36}$. Este «oscurecimiento» beato del ambiente hasta entonces luminoso del domus irrita a la nueva generación de la casa y si bien la discreción de Thomas le impide expresarse abiertamente al respecto, el temperamento provocativo y descarado de Tony no puede reprimirse.

El piadoso Cónsul querría hacer depender de la voluntad divina incluso aquellos hechos que sólo encuentran explicación en las confabulaciones de gentes inescrupulosas. Se resiste a creer que tras el fracaso del primer matrimonio de su hija exista una escarnecedora conspiración, matrimonio que, por otra parte, él promovió en atención a riguroso cálculo económico y a favor del cual empleó el argumento de la responsabilidad de cada miembro ante la historia de la familia como chantaje emocional frente a las volubilidades de su hija. Ha sido la voluntad de Dios, se dice cuando, acorralado, le presentan las pruebas de la existencia de la conspiración.

Este fatalismo, cuando pierde incluso su condición de bálsamo para la conciencia, se destapa como un síntoma de la involución de la saga. Y, sin duda, esta versión fatalista de la ascesis puritana es la clave del personaje del Cónsul: no afirma en modo alguno que la inclinación perseverante hacia el trabajo y la inversión racional de energías en la empresa de que se trate puedan ni deban ser sustituidas mágicamente por la confianza en el favor de los designios divinos; pero sí cree que la mano invisible de Dios se esconde tras cada comportamiento individual. No hay, por ello, que relajar los hábitos o relativizar la importancia del recto esfuerzo personal. Desde luego que confía en un sistema de castigos y recompensas en esta vida proporcionado a las virtudes

36 BudD., p. 251. 
profesionales de cada cual, confianza que es uno de los pilares del burguesismo y que podríamos denominar como fe en la racionalidad ética del mundo. Simplemente está persuadido de que tanto la presencia como la ausencia de esta rectitud profesional coinciden necesariamente con la voluntad divina. Así lo expone en presencia de su antecesor a raíz del progresivo declive y ulterior desaparición de la familia Ratenkamp, anterior propietaria de la mansión con cuya inauguración a cargo de los Buddenbrook se abre la novela. La ruina de la familia Ratenkamp se debió, según se cuenta, a una insensata y descabellada asociación financiera. Comprobemos cuál es la interpretación del Cónsul Buddenbrook:

— «Cedió a una especie de presión que me parece comprensible... ¿Qué es lo que le obligó a asociarse con Geelmaack, que tenía un capital irrisorio y una muy discutida reputación? A mi juicio, debió de sentir la necesidad de descargar en alguien una parte de su tremenda responsabilidad, pues presentía que se iba inevitablemente a pique... La casa había terminado su misión. La vieja familia había “passé”.» (...)

— «¿Así, su opinión señor Cónsul (...) (interviene, muy significativamente, un pastor protestante) es que, aun sin la intervención de Geelmaack y su descabellado modo de proceder, las cosas hubieran tenido el desenlace que tuvieron?»

— «Tanto como eso, no (...). Lo que creo es que Dietrich Ratenkamp tenía que unirse, necesaria y fatalmente, con Geelmaack, a fin de que pudiera cumplirse el destino... Obró bajo la presión de una inexorable fatalidad... Estoy persuadido de que conocía perfectamente todos los enredos de su socio y de que no ignoraba la situación de la casa. Pero el hombre se encontraba paralizado...» ${ }^{37}$

El Cónsul es demasiado sensible al destino del malhadado y anuente señor Ratenkamp como para no estar él también contaminado por la misma parálisis que llevó a aquél, según su interpretación, a consentir con su propio declive. En las palabras de Johann hijo se espeja su propio destino y, sobre todo, el de Thomas Buddenbrook, su sucesor. Son palabras que, en este momento inaugural de la saga, adquieren el espesor de un arquetipo, es decir, delinean misteriosamente un modelo o pauta primordial en que se reflejará el decurso del linaje de los Buddenbrook: el destino no hará sino retornarlos al punto en que aquella otra estirpe que les antecedió en la posesión del domus se extinguió.

37 BudD., pp. 22-23. 


\section{El senador Thomas Buddenbrook}

El proceso de descomposición de la familia entendido como desactivación ética de la vocación culmina en la figura de Thomas Buddenbrook, el padre de Hanno. De hecho, la existencia de este último no adquiere un sentido moral sino por confrontación con la realidad y las exigencias paternas. Mann consigue con el personaje de Thomas un acabado retrato de personalidad bifronte: entre lo que aparenta y lo que siente, entre lo que siente y lo que exige... hay una distancia tal que cualquier intento de salvarla le consume las fuerzas. Es verdad que nos es presentado como candidato ad hoc para satisfacer el tipo ideal de varón Buddenbrook y también es cierto que pronto asimila el credo familiar: afán de trabajar, de vencer, de llegar; la avidez de subyugar a la felicidad... todos estos sentimientos delataban, cuando menos inicialmente, la contundencia con que sabría responder a la vocación comercial.

Pronto arraigó en él la conciencia de la renuncia y la lucidez necesaria para percatarse de la proximidad de ésta al sentido del deber. Habiéndose entendido con una humilde florista de su ciudad, se compromete con una mujer de su posición, Gerda Arnoldsen, mujer distante y de frío carácter que desempeña un papel capital en la trama: ella introduce la música en el universo de los Buddenbrook.

Pero el personaje de Thomas, sin duda el más matizado y complejo de la novela, se sostiene de continuo sobre un equilibrio precario, hasta el esperpéntico derrumbamiento final. Algunos de los pasajes más intensos de Los Buddenbroock están dedicados a confrontar directa o indirectamente su persona con la de su hermano Christian, el díscolo vástago de los Buddenbrook, caracterizado a la manera de un Bufón o Joker ${ }^{38}$ que se convierte a lo largo de la trama en algo más que en el desazonador contrapunto al hieratismo y respetabilidad del Senador Thomas Buddenbrook. Frívolo, bufonesco e indócil, Christian carcome la virtud de la familia; su mera existencia le resulta tanto más inasimilable a Thomas cuanto más consciente es, secretamente, de que aquel Joker inconstante encarna todo lo que él mismo oculta a sí y a los demás. Un alter ego que, recurriendo a un mito de

38 Y cuyo diseño caracterológico se conviene muy bien con el de la figura mitológica del Trickster, hasta el punto de hacernos sospechar que Thomas Mann pudiera haberlo tomado como modelo para su Christian. Posteriormente a la publicación de Los Buddenbroock, Radin, Jung y Kerenyi dedicaron un ensayo a este personaje mitológico: locuacidad e intromisión, indiscreción y egotismo, indocilidad y corrosividad, son algunos de los rasgos que hermanan a Christian Buddenbrook y al Trickster. 
creación literaria, podríamos definir como un Mr. Hyde transplantado desde las brumas victorianas a la conciencia profesional hanseática, un elemento verdaderamente perturbador de la ascesis protestante. Veamos en qué reside precisamente esta corrosividad ética:

«Le falta algo, eso que podríamos llamar equilibrio, el equilibrio personal (dice Thomas a su hermana Tony al respecto de Christian), por una parte, no es capaz de disimular las desmañadas ingenuidades de otras personas..., no sabe paliarlas, pierde completamente los estribos... En cambio, por otra, suele perderlos también en el sentido de que se mete en las charlas más desagradables, revelando sus intimidades más recónditas. A veces se complace en cosas excesivamente lúgubres. (...) ¡Oh, todo se reduce a que Christian se ocupa con exceso de sí mismo, de los procesos de su propio yo! (...) Lucha con las palabras como si se esforzase en expresar algo prodigiosamente distinguido, misterioso, original. Una cosa quiero decirte (...) Yo también he reflexionado algunas veces sobre esa inquieta, frívola y curiosa carrera (se refiere al Teatro, a la carrera de actor, lo cual no dejará de tener su importancia, como veremos) porque, lo mismo que él, he sentido cierta atracción hacia ella. Pero he observado que le vuelve a uno desquiciado, incapaz e inconsciente..., y para mí el equilibrio es lo principal.»

Y, a continuación de esta velada confesión, reveladora de las íntimas amenazas que acechaban su vocacional disponibilidad hacia el comercio, discrimina Thomas entre la expansibilidad propia del artista y la contención burguesa. Lo más relevante es que discrimina una de otra en virtud del criterio de justificación, es decir, decide acerca de la pertinencia de una u otra cualidad en función de si están o no derivadas de un valor principal: la profesión interpretada como vocación:

«Siempre habrá hombres en quienes esté justificado ese interés, ese espíritu de observación; poetas capaces de expresar con acierto y belleza esa íntima existencia suya e inflamar con ello el mundo de los sentimientos de los demás. Pero nosotros no somos más que comerciantes, chiquilla, y el estudio de nuestras reacciones íntimas no tendrá interés para nadie. En último caso podemos admitir que los sonidos de una orquesta nos causan un placer considerable y que incluso, alguna vez no sabemos por qué no queremos tragar... Pero más no, ¡hemos de ser positivos, qué diablos, y hacer algo útil, como lo hicieron nuestros padres y abuelos...» ${ }^{39}$

39 BudD., pp. 276-77. 
La claridad de ideas que exhibe Thomas está, en realidad, asediada por aquella corrosión ética que le repugna en su hermano. Sus palabras son presas de la misma tensión que atenaza sus esfuerzos profesionales: tensión entre la despejada conciencia del deber y el afloramiento de una sensibilidad impertinente e inclasificable. Lo uno le lleva a reconocer efectivamente la vocación comercial como la suya; lo otro a una incontenible introspección que consume sus energías. Ambos procesos se resuelven finalmente en la necesidad de aparentar, necesidad que, en la medida en que se convierte en el eje de su vida, acentúa aún más su asfixia interior y lo aboca a un final patético.

La fuente del éxito de su abuelo había sido aquella razón ilustrada y escéptica en que se apoyó su acuidad en los negocios, su fe en la disciplina interior y el despejo con que obraba. Su padre, en cambio, derivó su fortuna de la voluntad divina, subrayando el carácter misional de su vocación; su piadoso fatalismo no le exoneró en ningún caso de reconocer en el esfuerzo y la probidad profesional un indispensable valor ético. Thomas, sin la pragmática exuberancia del anciano Buddenbrook y falto de la confianza puritana en los designios ultramundanos, se refugia en el Yo: es un Yo sobrio, disciplinado, quien ha de responder a la vocación burguesa para el comercio. La fortuna mundana es fruto de la dominación del alma, el éxito es el resultado de la contención del alma dentro de los límites que establece la condición de elegido. Los peligros y acechanzas que minan la respuesta personal a la vocación no provienen del mundo exterior sino de uno mismo. Son sus propios fantasmas quienes asedian la fortaleza del yo. La incertidumbre acerca de la propia condición de elegido es ya un elemento debilitador de las energías necesarias para arrostrar dicha condición.

Lo que Mann está investigando a través del personaje del senador Thomas no son sólo las claves éticas del éxito profesional en un marco cultural protestante sino, tal y como vimos al principio del trabajo, las posibilidades de edificar un moderno mito escatológico a partir de la idea de vocación. La viabilidad de tal empresa en el interior de una ficción novelesca pasa por el establecimiento de una nueva relación entre el mundo exterior y el mundo interior. La fortuna en los negocios no renueva el vigor de quien los acomete ni el éxito mundano, exterior y tangible, refuerza la disciplina interior. Para Thomas, la relación entre lo exterior/interior es más bien la inversa: no son los acontecimientos externos los que determinan tal o cual respuesta interior sino que es ésta la que determina el sentido del acontecer exterior. Esta interpretación está presidida en el caso del senador Thomas Buddenbrook por el 
sino fatal de los mitos del fin, es decir, está impregnada por el anuncio de la entrada de la muerte en el mundo:

«¿Qué es el éxito? Una fuerza, una prudencia y una aptitud enigmática, indefinible...; la conciencia de imprimir un impulso al movimiento de la vida con la propia personalidad...; la fe en la docilidad de la vida a nuestros mandatos... La felicidad y el éxito en nosotros y debemos sujetarlos fuertemente, con tesón. En cuanto aquí dentro empieza a aflojarse algo, a soltarse, a fatigarse, ya todo a nuestro alrededor se resiste, se rebela, se sustrae a nuestra influencia... Y entonces se marcha fracaso tras fracaso, y el hombre está vencido. (..) Sé que con frecuencia las señales de la felicidad externa y perceptible, los indicios del encumbramiento, aparecen cuando en realidad todo camina ya hacia su ocaso. Estos signos exteriores necesitan tiempo para manifestarse, del mismo modo que la luz de muchas estrellas del firmamento aparece en el instante en que no sabemos exactamente si al divisarlas es cuando empiezan a extinguirse o tal vez se han extinguido ya, mientras siguen brillando...» ${ }^{40}$

Lo que da tanta fuerza a la idea de vocación en Los Buddenbrook es, precisamente, esta nueva relación entre lo interior/exterior. Es el Yo quien se «apropia» del mundo: domina el mundo dominándo-se. En la medida en que esta disciplina interior ceda, el caos se irá apoderando del mundo. Un yo disperso y de voluntad huidiza habrá de responder ante un mundo devenido en un rosario de estímulos indescifrables. Dar a la vocación el sentido de justificación vital significa tanto como hacer de cada yo una cosmogonía. ¿Qué ocurre cuando ese yo, asediado por mil preguntas, cede definitivamente desactivándose su impulso? Sencillamente, que el mapa o la representación del mundo exterior que había sido capaz de configurar se hace ininteligible: sus «accidentes» no remiten ya a una unidad que les dé sentido, apareciendo como fragmentos de un mundo extinto o como borrosos reclamos de una realidad esquiva, sustraída a la influencia moderadora de la personalidad. Desde esta perspectiva, el senador Thomas Buddenbrook es portador de la misma semilla de confusión y parálisis que brotó en el albor de la postmodernidad.

Mann traduce muy acertadamente todo este fenómeno en términos temporales. Ya puso en boca de su personaje un bello símil (acaso los deslumbradores signos externos de su fortuna no sean sino la luz de una estrella muerta o que inicia, quizás, su desintegración en el

40 BudD., p. 438. 
momento en que más claramente se divisa su luz...); y le concede también la posibilidad de verter a la línea del tiempo este espejismo en que se ha convertido su encumbramiento social. Mann trabaja con dos formas temporales de cuyo desajuste obtiene el narrador jugosos réditos dramáticos: la primera forma responde al curso de la vida del personaje, es un tiempo biográfico encarnado por un movimiento de cuya continuidad se encarga la adición de los más variados hechos y circunstancias. Pero la sujeción a esta forma temporal no es suficiente para el novelista. La ficción está obligada a reconocer un sentido en cada uno de los hechos y circunstancias que la constituyen. Para dar cuenta de ese sentido - cuya interpretación será la que genere una u otra emoción, una u otra inteligencia, en el lector- el narrador ha de trabajar con otra forma temporal: el tiempo interior. Este tiempo no informa ya acerca de si tal o cual hecho ha tenido o no lugar, ni de cuáles fueron las circunstancias bajo las que se produjo; propiamente hablando, no nos informa de nada.

El movimiento en que se encarna corre subterráneamente a la línea de la biografía. Es un tiempo subterráneo. Como tal, puede adquirir compromisos diversos con el tiempo de la superficie. En su relativa autonomía, este tiempo interior traduce los hechos de la ficción por ideas. En calidad de tales, los hechos se liberan de las servidumbres de las circunstancias, excediendo los límites de una vida: el tiempo interior no da noticia de algo, lo relaciona con algo de lo que, quizás, no tenemos aún noticia; no entera al lector enunciativamente de tal o cual acción sino que lo hace sensible al diálogo que se esconde tras cada enunciado.

Conforme a la lógica pregunta-respuesta el lector puede lanzar hipótesis acerca del futuro del sentido de la trama o puede retrotraerse en el tiempo descubriendo presagios donde sólo había, aparentemente, afirmaciones. Cuando la ficción articula este tiempo interior insta al lector a desempeñar un papel eminentemente creativo: le insta a circular libremente por el interior del tiempo de la ficción. Le exige, en otras palabras, atender al poder metaforizador del texto, a cómo transporta éste el sentido de la voz narrativa presente hacia un sentido figurado en virtud de ciertas relaciones o parecidos ocultos hasta entonces. El senador Buddenbrook es sensible a este desdoblamiento de las formas del tiempo cuando, en el pasaje transcrito, traduce su encumbramiento social por la idea de la muerte. La apoteosis del éxito es un hecho que afecta al tiempo biográfico. La novela da cuenta de este hecho con escrupuloso sentido de la linealidad biográfica. Pero cuando Thomas Buddenbrook transfigura los hechos en presagios, es el tiempo interior el que está funcionando. El tiempo interior arranca lo virtual del fondo 
de lo real. Sólo desde él se puede ver un anuncio de la muerte en medio del esplendor.

El senador Thomas Buddenbrook es consciente de este desdoblamiento de las formas temporales en la medida en que experimenta íntimamente su desajuste. Las manifestaciones exteriores del éxito, que tan favorablemente afectan a su tiempo biográfico, no se compadecen en absoluto con las energías de que es capaz de disponer a la hora de responder interiormente a su vocación. Puede que su tiempo interior esté también passé, que se encuentre realmente agotado y se esté alimentando externamente de un tiempo prestado por una muerte que se complace malévolamente en regalarle esquivos fulgores. Esta pérdida del tiempo exterior en tanto en cuanto sustraído al poder modelador del yo revela la condición ilusiva de toda la realidad. Condición que alcanza también a la persona del Senador, como veremos.

Sin duda, las lecturas tempranas de Mann influyeron decisivamente en su interpretación del concepto de decadencia: Paul Bourget y sus Essais de Psychologie contemporaine están a la base de alguna de las consideraciones del escritor sobre su decadente personaje ${ }^{41}$. Bourget intentó en su obra dar cuenta de la terrible palabra (decadencia), concediendo que lleva en sí el signo de una grave crisis, pero proponiendo a su través valores artísticos en general, y literarios en particular, que le son específicos. No podemos entrar a discutir las propuestas de Bourget; tan sólo quisiéramos destacar algunas de sus ideas por lo que respecta al comentado desdoblamiento del tiempo exterior/interior. Efectivamente, Thomas Buddenbrook tiene mucho de aquellos decadentes que hicieron de su propia alma la materia de su arte; la abundancia de sensaciones delicadas y la exquisitez de los sentimientos más extraños les convirtieron, dice Bourget, en virtuosos, estériles pero refinados, de placeres y tristezas... Esto, con ser problemático, puede resultar en cierta medida estimulante como un arte para tiempos de crisis; pero que un burgués que debe responder con despejo y vigor a la vocación del comercio se vea reflejado en tal virtuosismo, supone tanto como reconocer que su personalidad está marcada por el signo de la fêlure (tara).

Thomas Buddenbrook se abandona a sus fantasmas, no se resiste a la autoexploración, se abisma en la contemplación inmoderada del yo y

41 Bourget, Paul, Essais de psychologie contemporaine, París, Plon, 1883, ed. revisada 1899. Ver I, pp. 18-25. Thomas Mann leyó a Bourget en fecha tan temprana como 1895 , antes incluso de que comenzara a familiarizarse con Nietzsche. Mann refiere de estas lecturas en sus cartas a Otto Grautoff e Ida Boy-Ed: MANn, Thomas, Briefe 1894-1901 y Briefe 1903-1928, Frankfurt am Main, S. Fischer, pp. 30 y 62 respectivamente. 
sus misterios... La literalidad del término «introspección» hace justicia a su actitud: mirar adentro. Lo que interesa a Mann es revelar cómo esta actitud introspectiva mina las energías que habrían de encauzarse hacia la vida comercial, carcomiendo toda su espontaneidad. Bourget estudió los posibles efectos de esta hipertrofia de la vida de la consciencia y situó entre ellos el dédoublement de la Psyche (desdoblamiento de la psique). Este desdoblamiento se comprueba en el senador: una sola psique desdoblada en su obligación de pensar y actuar, de un lado, y en su tendencia hacia la observación y el juicio, de otro. Este dédoublement es afín a aquel proceso de desencantamiento de la realidad que trajo consigo el imperio de la razón técnico-instrumental. Sin embargo, Thomas Mann no asume, en este sentido, mayores compromisos que los derivados del análisis de la progresiva automatización de la conducta externa del senador Buddenbrook. Cada vez más, aquella lejana inclinación hacia el mundo del teatro, que ya admitiera en los tiempos en que mostraba una respuesta más contundente y espontánea a su vocación, se va desembozando como lo que era en realidad: el germen malsano de la pérdida del equilibrio. La principal estrategia a que recurre Thomas Buddenbrook para compensar en su conducta externa la confiscación de la animosidad profesional a cargo de su enfermiza propensión a la autoexploración es el cultivo de las apariencias. En una palabra, el Senador adquiere la condición de actor.

«La vida de Thomas Buddenbrook no venía a ser sino la de un actor, pero la de un actor condenado a representar siempre, hasta en los más mínimos detalles, un solo y único papel que, salvo en contadas y brevísimas horas de soledad y laxitud, pone a contribución todas las energías y las devora... La absoluta carencia de un interés único, apasionado, que le absorbiera por completo, que uniera la pobreza y la desolación de su yo — desolación tan intensa que se hacía sensible sin cesar, como una bochornosa pesadumbre indefinida - con una interna noción del deber y una tenaz resolución de representar a toda costa, de vencer por todos los medios su postración y conservar los dehors, cada palabra, cada gesto, la más mínima de sus públicas acciones, en fatigosa y agotadora comedia.» ${ }^{42}$

El lector familiarizado con la obra de Mann quizás asocie esta agotadora comedia del senador Buddenbrook con aquel remozamiento cosmético a que se entregara Gustav von Aschenbach al final de La muerte en Venecia. Como héroe doliente Thomas Buddenbrook asume rasgos

42 Budd., p. 613. 
que Mann llevará a su culminación en la figura de Aschenbach ${ }^{43}$. Al igual que Thomas Buddenbrook, Gustav von Aschenbach (literalmente, arroyo de ceniza) pugna por ocultar ante el mundo que su disciplina interior se tambalea. Ambos erigen una mentira en el centro de sus vidas:

43 Véase Mann, Thomas, La muerte en Venecia, Barcelona, Edhasa, 1984, pp. 108 y ss. Dentro del capítulo Mann and the Prisonhouse of the personality, Harvey Goldman dedica una atención especial a la figura de Gustav von Aschenbach, estableciendo un fructífero diálogo entre su respuesta a la vocación y aquélla que demostrara el personaje de Tonio Kröger en la novela homónima. No podemos entrar aquí a valorar las conclusiones a que llega Goldman, en todo caso están entre lo más estimulante de su trabajo. Véase GoLDMAN, pp. 168-208. El mismo autor estudia particularizadamente el personaje de Tonio Kröger bajo el título de The Artist with a Bourgeois Identity: Tonio Kröger. Goldman, pp. 85-108. Aunque nuestro propósito es poner en relación, exclusivamente, el universo ético de Los Buddenbrook con el de Max Weber por medio de las ideas de vocación y ascesis, sí creemos conveniente apuntar, en cambio, que hablar de una posible relación entre las figuras de Thomas Buddenbrook (1901) y Gustav von Aschenbach (1912) obliga a dar cuenta de una serie de inflexiones en el tratamiento del concepto de vocación cuyas etapas intermedias están representadas por: Tonio Kröger (1903), Schiller, protagonista sin nombre del relato Schwere Stunde (Hora difícil, 1905, aunque publicado tardíamente, en 1921) y Klaus Heinrich, el héroe de Königliche Höheit (Alteza Real, 1909). En el personaje de Tonio Kröger ensaya Mann una posible conciliación entre la respuesta a la vocación artística y el orden de vida burgués: Admiro a los orgullosos y fríos que se aventuran por las sendas de la belleza grande - concluye Tonio al final de la obra-, la belleza demoníaca, y menosprecian al «hombre»... pero no los envidio. Pues si algo es capaz de transformar al literato (Literat) en poeta (Dichter), es este amor mío, tan burgués (Bürgerliebe), por todo lo humano, vivo y normal. MANN, Thomas, Tonio Kröger, Barcelona, Edhasa, 1994, p. 197. Con la introducción de la personalidad de Schiller en el relato Hora difícil, Mann aporta un matiz nuevo a su visión del concepto de vocación: el sufrimiento redime todo, todo lo santifica, parece ser la consigna del poeta. La personalidad del artista no se cimienta sobre las diversas realidades de su vida: aislamiento, crítico distanciamiento, etc. Es el sufrimiento del artista bajo estas circunstancias lo que le justifica ante sí y ante los demás: El dolor... ¡Cómo le inflamaba el pecho la palabra! (...) El talento mismo, ¿no era dolor? (...) Egotista es todo lo extraordinario en la medida en que sufre. Queréis acaso miraros, dice, jvosotros que carecéis de una misión (Sendungslosen), vosotros que lo tenéis todo mucho más fácil sobre la tierra! Y la ambición dice: ¿ha de ser mi sufrimiento en vano? ¡Me ha de engrandecer! ManN, Thomas, Frühe Erzählungen en Gesammelte Werke in Einzelbänden, Frankfurter Ausgabe, Peter de Mendelssohn, editor, Frankfurt am Main, S. Fischer, 1981, pp. 380-81. Schiller es el poeta sentimental revestido con los atributos del artista moderno: esclavo de una hipertrofia del elemento crítico de su consciencia, lucha contra la pérdida del vibrante sentido de la comunicación, de la ingenua expansibilidad y, finalmente, exhausto y presa de cierto rencor excluyente (vosotros que carecéis de una misión), cree encontrar en el sufrimiento la ley moral, la fuente de su fe en el arte y la vida... una experiencia trágica que deviene en una religión trágica. Aunque con cierta reserva, podríamos afirmar que el Schiller de Schwere Stunde es el Thomas Buddenbrook del arte. La reserva consiste en que Schiller reconoce un valor último y supremo por el que auto-inmolarse, como si se tratase de un caballero trágico para quien el sufrimiento es la patente de la nobleza. De nobleza se ocupa también Mann en su novela Königliche Höheit. Para el príncipe de Alteza Real la representación de su papel, presentarse ante el mundo bajo una for- 
cuando el placer de desempeñar un papel desaparece, sólo queda la máscara. La máscara sirve a Buddenbrook y Aschenbach para perseverar en sus obligaciones representativas, el uno ante el senado de su ciudad, el otro ante el mundo de las letras; pero cada vez se hace más grave la artificialidad de su condición de elegidos. Por lo que se refiere a Thomas, se puede decir que se halla atrampado en una penosa performance que le impide controlar el mundo exterior con la fuerza de una voluntad movilizada en la vocación ${ }^{44}$.

Ha desaparecido el impulso racionalizador en que habría de substanciarse la respuesta a la vocación. La consecuencia más importante

ma idealizada, supone la clave de su auto-aceptación. En Alteza Real, Mann analiza la vida de la realeza como una existencia puramente formal, una existencia supra-objetiva: la vida de Klaus Heinrich carece del espesor de la vida cotidiana. La vocación para la representación es no sólo la fuente del sentido de la vida del príncipe sino también una suerte de «coraza» que blinda sus respuestas ante el mundo: Vos vinisteis al mundo para aparentar -le dice Imma, en quien Klaus Heinrich ha depositado sus esperanzas de redención y casándose con la cual espera el príncipe «ingresar» en la vida-y, ahora, de repente, ¿debería creeros cuando decís que en Vos hay también algo sincero? (...) He observado a menudo que Vos habláis y manifestáis una opinión, pero lo mismo podríais manifestar otra, ya que, en realidad, Vos no poseéis ninguna opinión ni creencia en absoluto, y nada os preocupa excepto vuestra condición de Príncipe. Decís en ocasiones, que vuestro trabajo (Beruf en el original) no es fácil, pero, puesto que me habéis dado motivo para ello, quiero haceros observar que os sería mucho más fácil si Vos tuviérais una opinión y una convicción, Príncipe —ésta es «mi» opinión y «mi» convicción. ¿Cómo podría confiar nadie en Vos? No, no es precisamente confianza lo que Vos inspiráis, sino frialdad y embarazo, y aunque me esforzara en acercarme a Vos, esa especie de embarazo y torpeza me lo impediría. MANN, Thomas, «Königliche Höheit» en Gesammelte Werke in Einzelbänden, Frankfurter Ausgabe, Frankfurt am Main, S. Fischer, 1984, pp. 306-7 y 309-10.

${ }^{44}$ Goldman insiste en el carácter cultural de la vocación, trabajando constantemente a partir de la dualidad naturaleza / cultura: Thomas no ha «nacido» para la vida en que ha de desenvolverse, nos dice Goldman, sino que ha sido «invocado» a ella (Called). La vocación no es acorde a su naturaleza sino que es un producto de la cultura. Nosotros nos abstenemos de realizar esta discriminación, que nos resulta especialmente problemática. Aquello que se mienta bajo el término naturaleza es, en ocasiones, más fácilmente interpretable como temperamento; pero aún adquiriendo mayores compromisos, el carácter cultural de la vocación es tan evidente en el patriarca Johann Buddenbroock como en su débil epígono, el senador Thomas. Aceptar que alguien «ha nacido para...» es tanto como desvirtuar el calado ético de su vocación: responder a una vocación supone adquirir una serie de compromisos éticos específicos ordenados a la configuración racional de la propia existencia en atención a un yo moderador. Haciendo justicia a esta definición la naturaleza en modo alguno es un «dato absoluto», lo «dado al hombre en nacimiento», sino el fruto de una configuración ética, un elemento plástico que ha de determinarse interiormente bajo el influjo de una vocación o llamada que es, en realidad, no una burda exhortación exterior sino una auténtica cultura del yo. Puede que uno se exprese con mayor propiedad cuando, al referirse a Thomas como ejemplo de personalidad en la que sólo queda la huella de la vocación, la hueca forma sin la encarnadura interior, diga que es la naturaleza, no la cultura, quien se ha vaciado de contenido. 
de esta pérdida es la ausencia de justificación no sólo para cada uno de sus actos sino para el conjunto de su existencia. Esta no se deriva de... un valor último que la autentifique sino que se abisma inquiriendo los problemas más abstrusos, en todo caso, aquéllos ante los que su inteligencia está más desprotegida. La estirpe de los Buddenbrook había forjado a lo largo de sus generaciones una idea de profesión afín al concepto puritano de vocación, idea cuya íntima naturaleza consistía precisamente en el desarrollo de un Ethos militar. Con el personaje de Thomas, la novela da cuenta no tanto del caso de un soldado cristiano sin guerra en que medir sus fuerzas, como del de un confuso caballero cristiano en medio de una guerra cuyo propósito no se le alcanza. Sin duda este hecho le lleva a entablar polémicas relaciones con sus raíces cristianas: el pietismo de su antecesor no conviene en absoluto a su espíritu, y, aunque ha flirteado en su juventud con el catolicismo, es incapaz de reconocerse en él: es lo cierto que estaba imbuido de un grave protestantismo, profundo y severo hasta el remordimiento y vivo hasta la pasión, se nos informa en la novela, para continuar lanzando invectivas contra el sentido externamente confortador del catolicismo: ¡No, ante el Altísimo, y en el último momento, no existe ningún auxilio externo, no hay mediación, ni absolución, ni engaño, ni consuelo! ${ }^{45}$. En esto Thomas Buddenbrook es fiel hasta la desesperación a la concepción, común a todas las ramificaciones de la ascesis protestante, de una distancia insalvable entre el orden humano y la divinidad. Es precisamente el reconocimiento de una tal distancia lo que promueve la metodización de la vida en la profesión y fortifica a la personalidad en la vocación. Efectivamente, la fuerte devaluación de la importancia de los sacramentos en la religiosidad reformada es proporcional a los recelos que mostraron ante sus mágicas virtudes: Sólo por sí mismo y con las propias fuerzas era preciso poner manos a la obra y, antes de que fuese demasiado tarde, desenmarañar el enigma: prepararse o marcharse desesperado... ${ }^{46}$. Sin recurrir a lo que se cree que son espurias intercesiones, Thomas Buddenbrook es sensible hasta sus más desesperadas consecuencias a la especificidad ética de la ascesis protestante: valerse por sí mismo, de la fuerza moderadora de la propia personalidad, a la hora de arrostrar los misterios fundamentales del destino individual. Y, sin embargo, el senador porta la semilla del desencantamiento en la medida en que ve segarse a sus pies el terreno en que habría de cultivarse su yo. El encantamiento de una vida no es cosa de magias sacramentales

\footnotetext{
45 BudD., p. 649.

46 Ibid.
} 
ni intercesiones divinas; aun reconociendo que la distancia que media entre el hombre y la divinidad es insalvable, la ascesis protestante se proponía como alternativa de vida en que poder fabricarse la certeza de la propia bienaventuranza, dotando a cada intervención humana en la esfera del trabajo de una prima psicológica de salvación que la convertía en parte imprescindible de un plan racional de autojustificación. En esto consistía el encantamiento de la personalidad en la vocación. Retratar la descomposición de todo este proceso es lo que hace de Los Buddenbrook una novela del desencantamiento.

\section{Sobre la muerte y su relación con la indestructibilidad de nuestro ser en sí}

El capítulo $\mathrm{V}$ de la décima parte de la novela nos presenta a un Thomas Buddenbrook fatigado de la contemplación de su propio vacío: "debo pensar» se decía casi en voz alta. "Debo ordenarlo todo, antes de que sea demasiado tarde...» ${ }^{47}$. El, el jefe de la razón social «Johann Buddenbrook», se entrega durante horas a la lectura de un olvidado volumen de metafísica, devorando sus páginas en una suerte de éxtasis. Era, nos cuenta el narrador, la satisfacción incomparable de asistir al espectáculo de un cerebro superior en el ejercicio de adueñarse la vida entera... esa cosa tan fuerte, tan cruel, tan grotesca. Se trataba de la complacencia del doliente que, frente al hielo y a la dureza de la vida, mantuvo siempre oculta sus penas y sus remordimientos y que de pronto obtiene, de mano de un grande, de un sabio, el derecho fundamental y solemne de sufrir a la faz del mundo, de este «mejor de los mundos posibles» del que se demostró, con gracioso sarcasmo, que es el peor de todos los imaginables ${ }^{48}$. El sabio de cuya mano se atreve el senador Buddenbrook a extrañas exploraciones es Arthur Schopenhauer. El volumen que tiene entre manos pertenece a El mundo como voluntad y representación. Y el capítulo en que se detiene con especial afección es el intitulado Sobre la muerte y su relación con la indestructibilidad de nuestro ser en si $^{49}$.

En este punto Los Buddenbrook adquiere la densidad que habrían de adquirir, por ejemplo, La montaña mágica en su capítulo «Nieve», o

47 BudD., p. 650.

48 Ibid.

49 Schopenhauer, Arthur, «Über den Tod und sein Verhältnis zur Unzerstörbarkeit unsers Wesens an sich», en Die Welt als Wille und Vorstellung, Wissenschaftliche Buchgesellschaft Darmstadt, 1961, vol. II, pp. 590-651. 
Carlota en Weimar con el despertar de Goethe, en el capítulo VII. La narración da cuenta de una visión, de una ensoñación, de una situación cognoscitivamente pura; pura en la medida en que no admite ninguna reacción proporcionada. Tras habérsele entregado, todo ingresa nuevamente en el orden que ella se encargó de perturbar. Se trata de una situación a la que, propiamente, no se le pueden encontrar causas de las que podría haberse derivado lógicamente. Por otra parte, no resulta posible descubrir nada que haya tenido lugar posteriormente por su virtud. Efectivamente, tras haber abandonado el volumen de Schopenhauer, el senador Buddenbrook siente una opresión casi insoportable sobre su cerebro burgués: ¿Qué será esto? (...) ¿Qué me ha ocurrido? ¿Qué he oído? ¿Qué se me ha dicho, a mí, Thomas Buddenbrook, consejero de esta ciudad...? (...) ¿Iba dirigido a mí? ¿Puedo soportarlo?50 Incapaz de asimilar el significado profundo de aquellas páginas, reacio a enrasarlas con el orden burgués al que se deben sus cotidianas exigencias, y, al mismo tiempo, urgido por sus propios demonios a desentrañar el sentido de la lectura, el senador se entrega al sueño... Es precisamente en ese duermevela de la consciencia, en el interregno entre el tiempo de la vigilia y la suspensión temporal propia de las fantasías nocturnas, cuando le adviene la visión ${ }^{51}$, como si el muro de la noche se abriese, descubriendo un panorama inconmensurablemente profundo y eterno, lleno de luz.

Anteriormente citábamos cómo Thomas Buddenbrook se respondía históricamente a los interrogantes de la perdurabilidad tras la muerte. Esta respuesta se apoyaba en su confianza en la perpetuación del honor de la estirpe en una línea sucesoria a la que no se atrevía a poner término. Ahora, definitivamente minada esta confianza, ni siquiera participa de la fe en las manifestaciones históricamente inmanentes de la inmortalidad. De la mano de Schopenhauer accede, sin embargo, a un estadio superior en la interpretación de la inmortalidad. El poder destructor de la muerte se trueca en potencia liberadora: era el penosísimo regreso de un camino errado, la rectificación de un grave error, la liberación de

\footnotetext{
50 BudD., p. 651.

51 Mann participa aquí del mismo interés que ha mostrado la novela moderna hacia este estado de duermevela de la consciencia como medio privilegiado para hacer justicia a toda la verdad de lo humano. La vaga fluencia de la mente, el entreverado de lo tangible y lo imaginario, la desinhibición moral, la concurrencia del presente y el pasado, el desprendimiento de la realidad inmediata, la dilatación de las facultades perceptivas, la investigación de las posibilidades del lenguaje... todo esto, que permite formulaciones muy diversas, fue perseguido por autores como Mann, en el capítulo Nieve de la Montaña mágica; Broch, en su Muerte de Virgilio; Joyce, en su Ulises - sobre todo en el cap. 18, correspondiente al monólogo de Molly Bloom-y en el Finnegans Wake, entre otros.
} 
toda clase de obstáculos y barreras, la reparación de una lamentable desgracia $^{52}$. El sentido de estas palabras sólo puede alcanzarse si lo relacionamos con la idea de personalidad que se edifica a partir de la ascesis profesional protestante y bajo la obligación de responder individualmente a una vocación impersonal. Sólo en la proximidad de la concepción reformada de profesión puede medirse el impacto de esta visión en el espíritu del senador. En la visión nocturna la «personalidad»e «individualidad» no se le aparecen como centros que galvanizan una serie de cualidades éticas específicas del espíritu del trabajo capitalista sino como obstáculos torpes, pertinaces y viciosos que le impiden transformarse, con la muerte, en otra cosa mejor. Yendo un paso más allá del larvado platonismo inherente a todas las concepciones cristianas, en virtud del cual se asocia al cuerpo la imagen de la cárcel (del alma), aquí es la personalidad edificada en la respuesta a una vocación la que se interpreta como una prisión: la prisión de la personalidad en la vocación. ¿Acaso hay algo más anti-burgués y perturbador para una conciencia construida al amor de la ascesis profesional protestante que reconocer que lleva en sí el germen, la semilla, la posibilidad de todas las capacidades, de todas las actividades del mundo... y lanzarse acto seguido a cuestionarse: ¿Dónde podría estar si no estuviese aquí? ¿Quién, qué, cómo podría ser yo sin ser este yo, si esta mi persona no me excluyese y mi conciencia no me separase de todo aquello que no es $\mathbf{y o}^{53}$.

Mann confronta aquí a la figura del senador Buddenbrook con el límite máximo de su conciencia, forzándola, no por casualidad en un ambiente de semi-inconsciencia, a arrostrar la máxima alteridad. Si la personalidad de su hijo Hanno es aún más débil, más angustiada y vacilante que la suya propia... ¿qué es en realidad para el senador un hijo? El no descansará en su hijo al morir, se dice en este duermevela, no se perpetuará en una personalidad que, como la de Hanno, se encuentra ya desde la infancia sustraída al poder benéfico y moderador de la vocación; tras la muerte él estará en todos aquellos que dijeron, dicen y dirán: Yo; y más que en ninguno, en aquél que lo diga con más entereza, con más aplomo, con más alegría... En ese espíritu puro, fornido, sereno y cruel que crece en algún lugar del mundo, se perpetuará cuando la agencia liberadora de la muerte le haya rescatado de la mísera ilusión de que yo no soy tan él como yo.

Aparte los innegables ecos Nietzscheanos que trufan la iluminación nocturna del senador, Mann enfrenta aquí el principio individuationis

\footnotetext{
52 BudD., p. 652

53 Ibid., pp. 652-53.
} 
(principio de individuación), sin el cual la ascesis burguesa consistente en el desenvolvimiento ético de una serie de compromisos profesionales carecería de su sentido altamente personalizado, con aquella consunción mística del yo que impediría remitir a una personalidad diferenciada éxito ninguno. La aniquilación del yo burgués y su liberación de la prisión de la personalidad, se proponen como imágenes de una fe alternativa al enfermizo declive de ese mismo yo atrampado en la vocación profesional: la cósmica expansibilidad post-mortem del yo se opone a su patética desintegración en esta vida.

\section{Algunas consideraciones temporales acerca del proceso de descomposición de la personalidad}

A lo largo de toda su obra Mann se preocupó de constituir la realidad temporal de cada personaje, de cada escenografía y cada situación dramática como si se tratara del afloramiento de un tiempo oculto y más profundo al que normalmente se refiere con el nombre de eterno presente. Esta doble articulación del tiempo le permite dotar a la realidad histórica retratada en la diégesis novelesca del espesor de la realidad mítica: a través de las contingencias temporales de una trama que, normalmente, está escrupulosamente contextualizada desde el punto de vista histórico (el ejemplo más claro es el Doktor Faustus, en el que el narrador nos va proporcionando de primera mano datos acerca de su contexto histórico), se expresa el tiempo originario del mito. No podemos entrar aquí en el análisis de las estrategias de que se sirve Mann para conseguirlo, aunque sí conviene insistir en que esta doble articulación no supone en modo alguno trabajar con los objetos narrados (con los hechos dramáticos) como si fueran las formas sensibles o las referencias de un tiempo codificado ${ }^{54}$ a partir de compromisos comunicativos

54 Los códigos, como sistemas de signos y reglas que permiten formular y comprender un mensaje, son siempre definiciones socioculturales. El concepto de tiempo no escapa, lógicamente, a ellos. Y es cierto que, de hecho, los acontecimientos dramáticos de la ficción pueden ser tomados como las manifestaciones sensibles de determinados códigos temporales que los «moldearan». Sería posible establecer un catálogo de «signos» temporales propio de las ficciones literarias, pero sólo a cambio de que se considerara a la realidad temporal de los fenómenos, hechos y objetos de la ficción como representación de la realidad temporal de los fenómenos, hechos y objetos de la naturaleza, o, mejor dicho, como representación de la interpretación socioculturalmente codificada de la realidad temporal de los fenómenos naturales. Lo que reclama Mann es un código temporal originario, que establezca las condiciones de derecho, y no sólo de hecho, bajo las que el tiempo articulado en la ficción literaria es real en sí mismo y no sólo de modo representativo o analógico. Para 
previos que funcionaría como la estructura, o, más plásticamente, como el «molde» de aquéllas. Los hechos dramáticos de la ficción no ilustran analógicamente ni representan como simples signos un código temporal instituido con independencia y anterioridad a la ficción sino que son manifestaciones del tiempo real, tan legítimamente real como el tiempo de cualquier otro hecho de cualquier otro orden de realidad. No están hechos a semejanza de manifestaciones reales del tiempo en virtud de un previo código sociocultural (los avatares del amor, la generación familiar, el avance de una enfermedad, etc., son interpretados en todas las sociedades y culturas conforme a códigos temporales muy diversos, códigos que hacen de estos fenómenos algo temporalmente comprensible y comunicable: se discrimina tópicamente sus secuencias, sus «pasos», inflexiones o etapas, etc.). Los acontecimientos dramáticos de la ficción son tiempo real expresado imaginariamente. No hay tiempo «imaginario» en la literatura de Mann, su literatura es una articulación creativa de un tiempo real. Articular el tiempo, máxime cuando media originalidad, significa cualificarlo: dotarlo de atributos o cualidades que provoquen su presencia ante la inteligencia y lo retornen al orden de lo visible. Lo que emociona al lector en Los Buddenbroock es el tiempo, el tiempo que cursa inexorable, el tiempo percibido en sí mismo precisamente gracias a hallarse fuera de sí, articulado en una ficción... Los Buddenbroock es una cualificación imaginaria de tiempo real, al igual que lo es La montaña mágica o José y sus hermanos, tan real como pueda serlo la cualificación del tiempo por medio del golpeo

ello, los hechos dramáticos han de dejar de ser interpretados como signos temporales. Desde el punto de vista temporal no son signos en absoluto. Son tiempo por sí mismos, no por la influencia moldeadora de códigos socioculturales. Es su modulación en el interior de la ficción lo que habilitará al lector para establecer diálogos con fenómenos históricos concretos. Y no sólo al lector. También el autor puede instituir estos diálogos en el interior de la ficción en virtud de la doble articulación del tiempo: por una parte, el tiempo de la ficción cambia como un todo, en continua modulación y, por otra, cambia la relación entre los objetos dramáticos que, envueltos en el movimiento total, disfrutan de su tiempo particular. Así, por ejemplo, la vida de Hanno Buddenbrook tiene su tiempo particular, que muda y se extingue con una consistencia dramática interna, que le es específica; pero, a la vez, su tiempo está envuelto por el tiempo total de la ficción, involucrándose en la modulación tonal del tiempo de la ficción. De igual forma que de la vida de un personaje, podríamos hablar de las posibilidades de la doble articulación del tiempo al respecto de una escenografía: la segunda Guerra Mundial en el Doktor Faustus, por ejemplo. El análisis de este caso habría de llevarnos demasiado lejos: la modulación de la novela entendida como un todo se inspira temporalmente en un acontecimiento dramático particular incluido en ella. Aquí el tiempo de la ficción no envuelve simplemente al acontecimiento de la guerra, con su propia consistencia secuencial, sino que se inspira en él a la hora de modular sus tonos, de vertebrar el movimiento único del tiempo del Doktor Faustus como un todo. 
de una raqueta en un partido de tenis o el apianamento de una nota en la interpretación de una aria musical, aunque, eso sí, diametralmente distinta a éstas.

Las cualificaciones ficcionales del tiempo real se sostienen sobre una estructura profunda, un código temporal originario en el sentido de «originante»: el tiempo del mito, recurrente, cíclico, eterno... el nunc stans, el eterno presente, lo denomina Mann. Pues bien, no existe una novela en toda la carrera del autor de Lübeck en que la mediación de este tiempo (del que los personajes no pueden hablar directamente, sólo con vaguedad y al amor de la ensoñación, la semi-inconsciencia o el duermevela...), en que el afloramiento de esta estructura profunda del tiempo, en medio de una situación cognoscitiva pura como es la visión nocturna de Thomas Buddenbrook, suponga una presencia tan desasosegante y desestabilizadora no ya para el personaje, que, a la postre, será incapaz de asimilar la verdad de la iluminación, sino para el decurso mismo de la novela: el eterno presente es en Los Buddenbrook el símbolo de la aniquilación. En un medio tan poco solícito a este tipo de formulaciones metafísicas como es el ascetismo burgués, la eternidad se convierte en la imagen misma de la exterminación:

«Las mentirosas formas mentales del espacio, del tiempo y aun de la historia - los afanes por la perduración de la fama en el tiempo, a través de las personas de los descendientes, el temor de una total disolución y descomposición histórica一, eran cosas de las cuales se emancipaba su espíritu y dejaban de constituir un obstáculo para comprender la eternidad. Nada empezaba y nada terminaba. Existía solamente un eterno presente, y aquella fuerza en él que, con amor tan doloroso y dulce, impulsivo y apasionado, amaba la vida, de la cual su persona no era otra cosa que una imperfecta expresión, aquella fuerza sabría hallar siempre la puerta de acceso a ese presente. $\rangle^{55}$

No cabe aquí la valoración neutra de las ideas de Schopenhauer. La ascesis racional protestante y la idea de profesión construida por mediación suya no es independiente de las mentirosas formas mentales del espacio, del tiempo y mucho menos de la historia. La ascesis racional necesita de la historia concreta. Su compromiso con la historia pasa indefectiblemente por la perpetuación del nombre en la persona de los descendientes. Y el temor a una total disolución y descomposición histórica forma parte natural de su patrimonio de miedos. No puede ser de otra manera, del mismo modo que las confusas y destempladas cavilaciones

55 BudD., p. 654. 
nocturnas del senador Buddenbrook no pueden pasar por encima de la influencia moderadora de la vocación, que, como una cultura del yo, no admite alternativas sino en su propio terreno. Pero Hanno Buddenbrook, su descendiente, un espíritu musical, no podrá responder vocacionalmente a su inclinación artística. El es la víctima definitiva de los flirteos de su antecesor con la perturbadora y anti-burguesa, es decir, anti-ascética, idea de eterno presente.

\section{La introducción de la música en el mundo de los Buddenbrook}

Gerda, la esposa del senador Buddenbrook, guarda las distancias con su familia política a lo largo de todo el relato. De hecho, esta reserva consiste en la fijación de unos límites entre sí misma y las preocupaciones de la familia. Y el medio privilegiado para tal demarcación es la música, su pericia con el violín. Podría decirse que es Gerda quien sustrae al joven Hanno del benéfico y ordenado curso comercial de la familia si, en realidad, tal curso no estuviera ya estancado en algún punto de la genealogía del muchacho. Es cierto que la ascendencia femenina es decisiva para orientarlo hacia la música, pero ello no deja de obedecer también, y en cierta medida, a un compromiso diegético del escritor Thomas Mann: la influencia materna hace dramáticamente verosímil lo que, en aquel ambiente extraño al arte, hubiera supuesto una extravagancia. La importancia de la figura de Gerda estriba en la repercusión de su influjo en un medio social que no reconoce a la música como objeto legítimo de vocación en el varón. Acercarse al personaje de Hanno Buddenbrook no puede reducirse a tratar del componente femenino del arte o de la maternal sustracción del hijo a la vida de los negocios. En realidad es inadecuado remitir el destino de Hanno a la influencia de una persona, pues su destino lo tiene cobrado en no menor medida que tenían cobrada la fêlure los Rougon-Macquart de Zola. Hablar de Hanno es hablar de sus orígenes. Insertarlo en el putrescente curso de la vocación profesional de la estirpe. Según esta perspectiva, que es a la que nos hemos sometido en este trabajo, la influencia femenina es decisiva en la medida en que dota al enfrentamiento final del epígono de los Buddenbrook con el pasado comercial de la saga de un cariz ético específico. Con Hanno, las reprimidas y atormentadoras inclinaciones del senador tienen nombre y apellidos: el arte, la música. Sintió de nuevo el daño que causa la belleza — se nos dice de Hanno, después de que éste, invitado por su madre, haya asistido a una representación de Lohengrin-y hasta qué punto la pasión aniquila el valor y las aptitudes tan nece- 
sarias en la vida ordinaria ${ }^{56}$. Hanno Buddenbrook no necesitará representar ante nadie lo que no tiene fuerzas para ser, sabe bien a qué se debe el saqueo de sus aptitudes y su ánimo para la vida, y conoce su nombre: la belleza, la pasión artística. No tendrá que convertirse en un actor (un actor de sí mismo) como su padre, ni se preguntará en una zozobra del pensamiento. ¿Qué será esto? ¿Qué me ha ocurrido? ¿Qué se me ha dicho? El mal de Hanno Buddenbrook es más grave. El «sabe» qué es esto, qué le ha ocurrido, qué le ha sido dicho. Ni siquiera se plantea, como su progenitor, si puede o no soportarlo. El senador abandonó sus flirteos con la verdad, sustrayéndose a ella, entre acobardado e indolente, para ingresar en el orden de la apariencia del que se veía definitivamente esclavo. Hanno es, en cambio, una de las más poderosas imágenes literarias de la muerte de entre las numerosas que pueblan la obra de Mann. Harvey Goldman lo llama «el protoartista». Y, efectivamente, Hanno no es uno de esos Joker a los que, aun sin faltarles el talento, carecen del Willen zum Werk (la voluntad de trabajar). Hanno carece no de la energía suficiente para trabajar sino de la energía necesaria para vivir.

No quiero la suerte; me hace daño, le dice a su único amigo, Kai. Realmente Hanno no sabría qué hacer con ella. El no representa al rebelde héroe novelesco que se subleva contra las imposiciones de la tradición de las que se hace portavoz un tiránico medio familiar. Nada más alejado de Los Buddenbroock. Hanno es incapaz de afirmarse levantisco frente a herencia ninguna, antes bien él es el fruto de una negación profesional. Si en su padre sólo quedaba la huella de la vocación, siendo cubierto el vacío ético por medio de grandes dosis de agotadora simulación y meticuloso cultivo de la apariencia, en el hijo hasta la huella se ha borrado y sólo queda el terreno yermo que debió ser hollado por la vocación. La frase que mejor define a Hanno la pronuncia él mismo: No puedo querer ${ }^{57}$. Si al senador le costaba horribles esfuerzos arrostrar la mínima contingencia profesional, a su hijo es

56 BudD., p. 698.

57 No se puede ilustrar mejor la completa desactivación a cargo del personaje de Hanno de la idea puritana del convenio (es decir, de la activa disposición o puesta en servicio humana ante la vocación divina), máxime si, tal como afirma Michael Walzer, recordamos que el puritanismo fue en cierto sentido la religión de los sociológicamente competentes, de aquellos que habían sido invocados (Called). WALzER, Michael, opus cit., p. 218. En el caso de que el joven Hanno tuviera alguna garantía de supervivencia se alinearía sin duda, ante la mirada de la conciencia religiosa puritana, con toda aquella humanidad que se resistía a convertirse en sujeto de control y disciplina, seres peligrosos (pícaros, mendigos, nobles gentlemen, frailes y criados...) por el mero hecho de vivir extramuros del mundo vocacional. Ibídem, p. 216. 
cualquier accidente de la vida lo que le reduce las fuerzas infundiéndole un miedo pánico. La quiebra de la personalidad en la respuesta a una vocación se extrapola ahora a la quiebra de toda una estirpe cobrada en la persona de alguien incapaz de querer nada, y, por lo tanto, incapaz de querer una personalidad construida por medio del perseverante cultivo de una serie de cualidades éticas específicas en el marco de la ascesis profesional protestante. La «inflación» de la debilidad adquiere con el decurso de la saga proporciones cósmicas al afectar radicalmente a la relación de la estirpe de los Buddenbrook con el mundo, con la totalidad del mundo (totalidad presente en su concepto de vocación). Esta cósmica inflación del quebranto y la debilidad se compadece perfectamente con la condición escatológica del relato, al mismo tiempo que garantiza, de modo devastador, la clausura del circuito ético entre profesión y vida.

No podemos dudar de la condición de elegido de Hanno Buddenbrook - pero tocaré, no puedo contenerme, aunque el hacerlo me empeore - . No obstante, como al respecto de todo elegido, no es tan importante que el medio en que se desenvuelve no conforte sus propósitos y se muestre opaco a sus intereses cuanto que la fuerza de su iniciativa sea capaz de «confortar» al medio, es decir, de autentificarlo o justificarlo. Sin embargo, frente al universo en descomposición de los Buddenbrook, ni Hanno puede legítimamente establecer cuáles son sus propósitos — ¿Con mi música, Kai? No haré nada con ella—, ni la música aparece revestida del vigor justificativo del que hasta entonces disfrutaba la vocación comercial.

Podríamos decir que el final de la estirpe de los Buddenbrook es un terreno propicio para el estudio caracterológico de la figura del artista. La tangencialidad de sus inclinaciones respecto a las cotidianas exigencias le permite librar batalla contra sus propios demonios, o seguirlos cautelosamente, a cambio de desguarnecer su personalidad ante los más nimios avatares de la vida e infundirle una insalvable nostalgia de aquella vida al abrigo que recordaba Flaubert. Sin embargo, reducir el papel de la música en Los Buddenbrook a estos o a semejantes cometidos descriptivos supone atribuir al joven Hanno una condición de «artista» que no se merece, además de un empobrecimiento de las virtudes simbólicas de la música. Precisamente Los Buddenbrook es la única novela de Thomas Mann en que el arte queda sin decir todo lo que podría y debería decir. A Tonio Kröger se le permite conciliar la expansibilidad propia del artista con la vida recta y ordenada característica del burguesismo, a Gustav von Aschenbach le arrebata de este mundo de sombras la presencia numinosa de una idea, la de la belleza, en el sentido platónico del término, pero esto ocurre después de que su carrera 
esté bien afianzada en el universo de las letras; es evidente que a Adrian Leverkühn se le otorga la posibilidad de decir todo lo que se puede decir musicalmente en $s u$ tiempo, sin escatimar (o, mejor dicho, con una presencia decisiva de ellos) los lados más negros de lo decible... y no cabe duda de que el pícaro Félix Krull consuma su arte prodigiosamente. En Los Buddenbrook, no. Y esto es así no tanto por la debilidad constitutiva de Hanno Buddenbrook como por el vaciamiento ético del concepto de vocación que afecta a esta saga religiosamente exhausta, incapaz de primar con la esperanza de la salvación acción profesional alguna. Lo primero habría de llevarnos a disquisiciones psicológicas que no vienen al caso en este trabajo; lo segundo nos permite afirmar que la presencia de la música en la novela certifica que los Buddenbrook se han quedado sin Dios a que servir.

Lo decisivo en el personaje de Hanno es que su relación con la música no es una respuesta personal a una vocación impersonal sino una extenuativa reacción morbosa frente al desencanto. Desde que murió mi padre - le confiesa a su amigo Kai-, tanto el señor Stephan Kistenmaker como el pastor Pringsheim no dejan un solo día de preguntarme qué es lo que quiero ser. ¡Pues no lo sé! No puedo contestarles. No deseo ser nada. Me da miedo todo. La inclinación de Hanno hacia la música es un esfuerzo anheloso de olvido y, no obstante, tiene mucho de éxtasis que embarga su alma del sentimiento de desolación. Las páginas que coronan el capítulo segundo de la undécima parte de la novela, un magnífico capítulo que relata un día en la vida del muchacho, recogen a Hanno Buddenbrook frente al piano ${ }^{58}$, disponiéndose a interpretar una sencilla melodía que, por medio de diversos juegos modulatorios y fantasiosas variaciones temáticas, adquiere una densidad musical

58 Acerca del intrínseco burguesismo de este instrumento véase WeBER, Max, «Los fundamentos racionales y sociológicos de la música», en Economía y Sociedad (Esbozo de sociología comprensiva), Fondo de Cultura Económica, México, D.F., 1983, pp. 1118-1183: Porque, pese a toda su esencia musical, el piano es un instrumento doméstico esencialmente burgués. En efecto, del mismo modo que el órgano requiere para el despliegue de sus posibilidades el local gigantesco, el piano necesita un local de proporciones moderadamente grandes. Todos los éxitos de ejecución de los grandes pianistas modernos no cambian en nada el hecho de que, al tocar solo en la gran sala de conciertos, el instrumento se compara involuntariamente con la orquesta y se encuentra, naturalmente, demasiado liviano. De ahí que los portadores de la cultura pianística sean los pueblos nórdicos, cuya vida, aunque sólo sea por razones de clima, se centra alrededor del «hogar», en contraste con el Sur. Debido a que en éste, por motivos de clima y de historia, el culto del hogar se ha ido perdiendo, el piano, inventado allí, no se propagó a pesar de ello tan rápidamente entre los italianos, según ya vimos, como entre nosotros (los alemanes), ni ha conseguido alli hasta hoy la posición de un «mueble» burgués en la misma extensión que entre nosotros se considera como natural desde ya hace mucho tiempo. Ver supra, p. 1183. 
insospechada. La estrategia narrativa de Mann recuerda sorprendentemente en este punto a aquella con que, en nombre de Serenus Zeitblom, habría de acercarse casi medio siglo más tarde al universo creativo de Adrian Leverkühn. La página parece realmente extraída del Doktor Faustus. Su intensidad elegíaca, la penetración y agudeza dramáticas de los comentarios del narrador sobre el «músico», sientan un curioso precedente para la vida del compositor alemán Adrián Leverkühn narrada por un amigo. La interpretación de Hanno es un auténtico Lamento, el infructuoso cultivo de un talento en un terreno yermo; el cosmos de los Buddenbrook se ha extinguido y la pasión musical de Hanno no puede restituirle una sola de sus piezas. La pulsación de cada nota al piano facilita la entrada de la muerte en el mundo de la saga.

«Había algo brutal y loco, de ascético y religioso, en el fanático culto de aquella nada, de aquel pequeño fragmento de melodía, pequeñísimo, pueril.. Y un placer morboso, también, en la inmensidad e insaciabilidad con que era gozado y sublimado. Tenía mucho de cínica desesperación; era un deseo de placer, un afán de ocaso, un anhelo de muerte, pero aspirado en una postrera dulzura, gustada hasta la extenuación... Y, al fin, más allá de aquel caos sublime sonó un prolongado y suave arpegio en modo mayor que, ganando un medio tono, pasó al menor y en él se disolvió, expirando en medio de melancólica inquietud...» ${ }^{59}$

Hará falta algo para que la música se atreva a decir lo suyo y propio a este tiempo climatérico. Thomas Mann aguardará hasta el Doktor Faustus para dar nombre a ese algo mediante el expediente de introducir la idea del pacto con el diablo. En Los Buddenbrook sólo queda, sin embargo, la dudosa esperanza en un más allá que pueda acoger a aquéllos que, como Hanno Buddenbrook, no pudieron forjarse en este mundo una personalidad al amor de una vocación. Su incapacidad para racionalizar el camino de la vida y someterlo ascéticamente al imperio de un destino (musical, en el caso de Hanno) representó la falta que trajo la muerte al mundo. La muerte definitiva, la que habría de exterminar a la estirpe comerciante de los Buddenbrook y es la fuerza victoriosa en los mitos escatológicos.

59 BudD., p. 738. 